\title{
A QUANTITATIVE ANALYSIS OF SUBURBANIZATION AND THE DIFFUSION OF THE AUTOMOBILE*
}

\author{
By Karen A. Kopecky AND Richard M. H. SuEN ${ }^{1}$
}

\author{
The University of Western Ontario, Canada; University of California, Riverside, U.S.A.
}

\begin{abstract}
Suburbanization in the United States between 1910 and 1970 was concurrent with the diffusion of the automobile. A circular city model is developed in order to access quantitatively the contribution of automobiles and rising incomes to suburbanization. The model incorporates a number of driving forces of suburbanization and car adoption, including falling automobile prices, rising real incomes, changing costs of traveling by car and with public transportation, and urban population growth. According to the model, 60\% of postwar (1940-1970) suburbanization can be explained by these factors. Rising real incomes and falling automobile prices are shown to be the key drivers of suburbanization.
\end{abstract}

\section{INTRODUCTION}

Suburbanization has been observed in cities throughout the United States since the late 19th century when omnibus, commuter railroads, and streetcars were first implemented. But technological progress in transportation made its biggest contributions during the 20th century with the invention of the automobile and later the modern highway system. The adoption of the private vehicle as the dominant form of transportation in the United States, combined with rising income levels, encouraged movement to less dense areas where housing was more affordable. The goals of this article are to (1) measure the contribution of automobiles to suburbanization during the postwar (1940-1970) period and (2) quantify the relative contributions of falling automobile prices, rising real incomes, changing costs of traveling by car and with public transportation, and urban population growth to suburbanization during the 1910-1970 period.

In order to achieve these goals, a monocentric city model is constructed in which consumers with different income levels can choose their residential location and mode of transportation. The model is calibrated to be consistent with, among other things, changes in car-ownership rates, prewar (1910-1940) suburbanization rates, and a number of statistics on commuting and travel. The calibration method is now commonly used in quantitative macroeconomic studies. In the urban economics literature, Chatterjee and Carlino (2001) adopt this method to explain the changes in employment densities across metropolitan areas in the postwar United States. The calibration method is particularly useful for this study due to the paucity of data for the early years. Under the baseline calibration, the model predicts that rising real wages, falling prices of automobiles, changes in the costs of traveling by car and public transit, and population growth can account for $60 \%$ of postwar suburbanization. A series of counterfactual experiments reveals that the rise in real incomes and the fall in automobile prices are the key drivers of suburbanization, whereas the growth in urban population has very little impact.

\footnotetext{
* Manuscript received in October 2007; revised in January 2009.

${ }^{1}$ This article benefited greatly from the advice of Jeremy Greenwood. We are also grateful for the valuable comments and suggestions of Richard Arnott, Mark Bils, Matthew Kahn, Josef Perktold, two anonymous referees, seminar participants at the University of Rochester and UC Riverside, and conference participants at the 2004 SED conference, the 2005 NBER Urban Economics Working Group Meeting, the 2005 Midwest Macro Meetings, and the 2006 Laboratory for Aggregate Economics and Finance's Housing Workshop. Please address correspondence to: Richard M. H. Suen, Department of Economics, Sproul Hall, University of California, Riverside, CA 92521. E-mail: richard.suen@ucr.edu.
} 
1.1. Suburbanization. Suburbanization refers to the spreading of urban population and employment from the central cities to satellite communities called suburbs. ${ }^{2}$ This movement results in an increased dispersion of urban population and employment over a land area. Although employment and population tend to move simultaneously, jobs have been more concentrated than residents throughout the period in question. As late as $1950,70 \%$ of jobs in metropolitan areas were located in the central cities whereas only $57 \%$ of residents were located there. In 1970 , $55 \%$ of jobs were located in the central cities compared to only $43 \%$ of residents (Mieszkowski and Mills, 1993). Thus, although the majority of firms were still concentrated in the central cities in 1970, a large portion of the urban population had already relocated to the suburbs. In light of these developments, this study focuses on explaining the suburbanization trend of the urban population and abstracts from employment decentralization. ${ }^{3}$

1.1.1. Measuring suburbanization. To measure the extent of suburbanization, researchers typically focus on how the population density function changes over time. The population density function is assumed to take the negative exponential form

$$
D(x)=a e^{-b x}
$$

where $D(x)$ is the population density (total residential population divided by total land area) at distance $x$ from the city center. The parameter $a$ provides an estimate of the density at the city center. The parameter $b$, known as the population density gradient, measures the rate at which population density falls with distance. ${ }^{4}$ The extent of suburbanization that occurred over a period of time can be captured by the percentage change in the population density gradient.

1.1.2. Historical facts. Suburbanization is a widely observed phenomenon in the United States, as well as many other countries around the world. In the United States, the growth of suburban areas began in the 19th century. Taylor (1966) reports that, between 1830 and 1860, population growth rates in the suburbs of New York, Philadelphia, and Boston were much higher than in the central cities and that by $1860,38 \%$ of Boston's population and $31 \%$ of New York's lived in suburban areas. Using the exponential density function described above, Mills (1972) finds that the population density gradients of Baltimore, Milwaukee, Philadelphia, and Rochester have been consistently decreasing since 1880 . Decreasing population density gradients have been observed for almost all American cities during the period 1910-1970, making it the most intensive period of suburbanization in the United States. Table 1 shows the evolution of the average population density gradient of 41 American cities between 1900 and $1970 .{ }^{5}$ The density gradient declined by $77 \%$ over this period, declining most rapidly during the 1940 s, when it fell by $36 \%$.

Part of the decline in population density gradient is due to the growth of urban population between 1900 and 1970. At the beginning of the 20th century, only 40\% of Americans lived in urban areas. However, by the late 1970 s, more than $70 \%$ did. Whereas the total U.S. population grew at an average annual rate of $1.4 \%$ during this time period, the comparable growth rate of urban population was $2.3 \%$. As the urban population increases, cities must expand spatially in order to accommodate more people. Population growth, however, cannot explain the entire

\footnotetext{
2 Hereafter the terms "suburbanization," "urban decentralization," and "urban sprawl" are used to refer to the same phenomenon.

3 Theoretical studies that allow identical firms and households to choose their locations simultaneously include, among others, Fujita and Ogawa (1982) and Lucas and Rossi-Hansberg (2002). Incorporating household heterogeneity and different modes of transportation into these models would greatly increase the complexity of the analysis and computation.

4 The exponential population density function was first introduced in Clark (1951). Subsequent studies have applied it to measure suburbanization in urban areas worldwide. See Mills and Tan (1980) for a survey of these results. See Mills (1972) and McDonald (1989) for more details on the estimation method.

5 Source: Edmonston (1975) Table 5-3. These cities were the 41 largest American metropolitan areas in 1900.
} 
TABLE 1

MEAN GRADIENTS FOR 41 CITIES THAT WERE METROPOLITAN DISTRICTS IN 1900

\begin{tabular}{lcccccccc}
\hline Year & 1900 & 1910 & 1920 & 1930 & 1940 & 1950 & 1960 & 1970 \\
\hline$b$ & 0.82 & 0.83 & 0.79 & 0.66 & 0.61 & 0.39 & 0.31 & 0.23 \\
\% Change & & 1.2 & -4.8 & -16.5 & -7.6 & -36.1 & -20.5 & -25.8 \\
\hline
\end{tabular}

Source: Edmonston (1975, p. 68).

suburbanization trend. Edmonston (1975) finds a consistent decline in population density gradient even after controlling for city population size. This shows that there are factors other than population growth that contribute to the suburbanization trend.

1.1.3. Theories of suburbanization. Suburbanization has been studied extensively over the years by urban economists, geographers, and historians. Some of the most popular theories are discussed below.

The standard theory of suburbanization, which is also the one developed and assessed in this article, proposes that the phenomenon is driven by a combination of technological progress and rising incomes. Transportation innovations such as streetcars, commuter rails, subways, and automobiles affect the spatial distribution of households by lowering the time cost of intraurban travel. In response to lower transportation costs, those who can afford the new technology move to outlying areas where cheaper land translates into more spacious houses and larger yards. As real incomes rise and technological progress drives a decline in the relative price of the new transport mode, more urban households adopt it and relocate to suburban areas. This process drives the expansion of metropolitan areas and the decline in their population density gradients.

The rise in real incomes in the United States since the 19th century has been well documented. As for transportation technology, a series of innovations in mass transportation has been continually introduced into American cities since the 1830s. ${ }^{6}$ Studies supporting the standard theory of suburbanization during the 19th century include the following. Warner (1962) notes that the introduction of streetcars into Boston likely caused the first major movement of affluent households to the suburbs during the 1850s and the 1860s. Taylor (1966) argues that the introduction of omnibuses, commuter railways, and streetcars between 1830 and 1860 encouraged city dwellers to live in outlying areas and travel to work.

By far the biggest technological breakthrough in transportation came with the invention of the automobile at the dawn of the 20th century. The extensive suburbanization observed during the decades that followed was concurrent with the diffusion of automobiles into American households. ${ }^{7}$ Glaeser and Kahn (2004) assert that the root of urban sprawl is the "technological superiority of the automobile." Using cross-sectional data from the United States as well as other countries, these authors find a strong positive correlation between low population density and automobile use. A more recent innovation in transportation technology was the development of highway systems, which were introduced into the United States during the 1950s. Using data from the period 1950 to 1990, Baum-Snow (2007a) estimates that the construction of a new highway that passes through a city's center reduces the center's population by about $18 \%$. As Baum-Snow states, the results of his study suggest that the construction of interstate highways can account for about one-third of the decline in the share of the metropolitan population living in central cities during the 1950-1990 period.

Along with technological progress in transportation, there is also evidence that rising real incomes played an important role in 20th century suburbanization. Margo (1992) estimates that

6 The first major innovation in mass transportation was the omnibus, which was commonly used in American cities during the 1830s. The following decades witnessed the introduction of commuter railroads and streetcars. For more details on these early inventions, see Taylor (1966). The next major innovation in intraurban transportation was rapid transit. The first underground rapid transit line in the United States was opened in Boston in 1897.

7 Historical facts about the diffusion of the automobile in the United States are reviewed in the next subsection. 
TABLE 2

PERCENTAGE OF HOUSEHOLDS OWNING AT LEAST ONE CAR, 1910-1970

\begin{tabular}{ccccccr}
\hline Year & 1910 & 1920 & $1934-1936$ & 1950 & 1960 & 1970 \\
\hline$\%$ & 2 & 33 & 44 & 59 & 77 & 82 \\
\hline
\end{tabular}

Source: See "Car-ownership" in the data section of the Appendix.

$43 \%$ of suburbanization in the United States between 1950 and 1980 can be explained by the increase in household income over this period.

The accelerated rate of suburbanization that occurred during the postwar period has inspired the development of other theories that attribute suburbanization to the social and economic factors that are peculiar to the postwar United States. Two common forms of these theories are described below. Between 1940 and 1970, there was a massive migration of black, southern households to the central urban areas in the north. This happened at a time when suburbanization of white households was at its peak. These observations inspired the so-called "white flight" theory, which states that whites relocated to the suburbs as a response to the inflow of black migrants. $^{8}$ In a recent study, Boustan (2007) estimates that about $20 \%$ of postwar suburbanization can be explained by this theory. Other studies suggest that postwar suburbanization is largely a response to the deteriorating social and economic conditions in the central cities (Bradford and Kelejian, 1973; Frey, 1979; Grubb, 1982; Mills and Lubuele, 1997; Cullen and Levitt, 1999). ${ }^{9}$ According to this theory, affluent households move to the suburbs to avoid problems in the central cities such as racial tension, high crime rates, low-quality public schools, and high taxes. Although the "white flight" and "central city disamenities" theories may explain some aspects of suburbanization, such as its accelerated rate in the early postwar period, the importance of these theories as primary explanations of suburbanization has been called into doubt by several authors (Mills and Price, 1984; Mieszkowski and Mills, 1993; Glaeser and Kahn, 2004). The massive inflow of black migrants is a postwar phenomenon, but the trend of suburbanization had begun long before World War II. In addition, suburbanization is observed in places that are not plagued by racial tension and crime. For instance, the rate of violent crimes is much higher in the United States than in Canada, but metropolitan areas in the two countries decentralized at similar rate during the period 1950-1975 (Goldberg and Mercer, 1986).

1.2. The Diffusion of the Automobile. The first automobiles entered the United States market in the late 1890s, initiating an adoption process that would continue throughout the 20 th century. In the early 1900s, the automobile, selling at more than five times average annual household earnings, was considered more as a toy for the rich than as a realistic mode of transportation. Even by 1910, only approximately $2 \%$ of American families owned a car. Starting in the 1910s, however, the rate of car-ownership began to increase quickly, driven by rapid price declines due to technological progress in production. By the mid-1930s, more than $44 \%$ of American households owned a car, and by $1970,82 \%$ owned at least one car and $23 \%$ owned two or more. ${ }^{10}$ Table 2 shows how the percentage of households owning at least one car increased over the period 1910-1970.

Rising real incomes and decreasing relative prices of automobiles fueled their adoption by American families. Not surprisingly, rich households tended to adopt earlier than poor

\footnotetext{
8 There is a large literature in sociology and urban geography that examines the causes and consequences of "white flight" over the period 1950-1970. For instance, Frey (1979) and Marshall (1979) analyze the factors that cause white people to relocate to the suburbs. Guest (1978) documents the changing racial composition in U.S. cities between 1950 and 1970, whereas Sorensen et al. (1975) and Farley (1977) report the extent of racial segregation during this time period.

9 Sociologists are also well aware of central city problems. Wilson (1987) provides a detailed account on the problems of violent crime, high rate of joblessness, teenage pregnancies, single-headed families, and welfare dependency in the inner city. Katzman (1980) and Sampson and Wooldredge (1986) consider the effect of high crime rate on suburbanization.

10 A detailed description of these data can be found in the data section of the Appendix.
} 


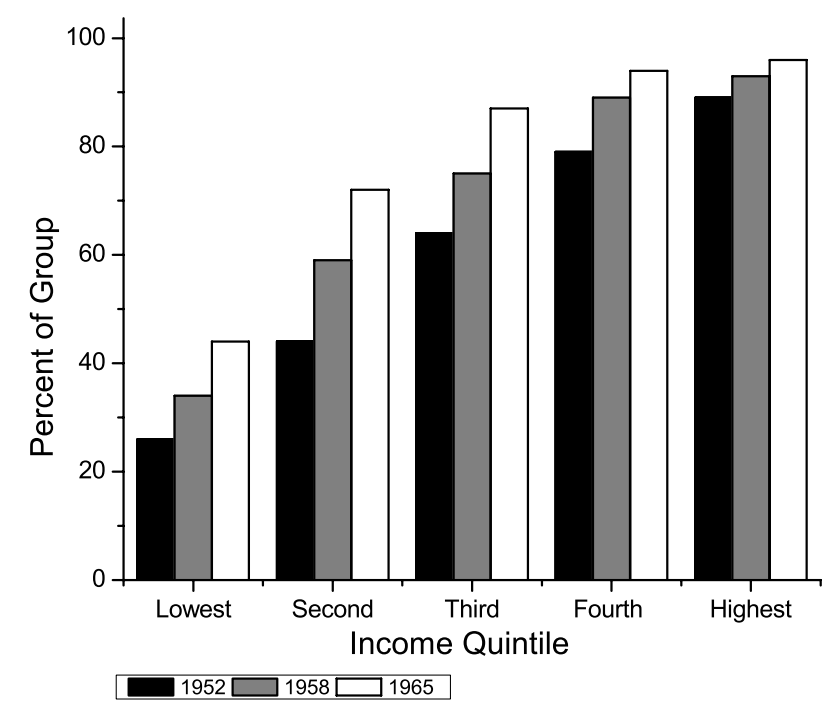

SourcE: Survey of Consumer Finances, University of Michigan.

FIGURE 1

CAR OWNERSHIP BY INCOME QUINTILE: 1952-1965

households. Figure 1 shows that for the period 1952-1965, car-ownership in American cities ranged from less than $50 \%$ for the lowest income group to over $90 \%$ for the highest one. Overall ownership increased from $65 \%$ to $74 \%$ during this period, largely due to increased adoption by households in the second and third quintiles. The quality-adjusted price of new cars fell by $88 \%$ over the period $1906-1970$ as shown in Figure $2 .^{11}$

There is also a linkage between car-ownership and residential location. Figure 3 shows that families living farther away from the city center are more likely to own cars than those living closer to the center, illustrating that households' residential location choice and car-ownership decision are interrelated.

1.3. The Analysis. The main objective of this study is twofold: first, to quantify the importance of the diffusion of the automobile in explaining postwar suburbanization and, second, to quantify the relative contributions of four factors, namely, rising real incomes, falling automobile prices, changes in transportation costs and urban population growth, to suburbanization over the period 1910-1970. In order to achieve these, a variant of the Alonso-Muth-Mills monocentric city model is developed. ${ }^{12}$ The model differs in three major ways from the standard model. First, the model studied here allows for heterogeneity in household income. Hence it is able to make predictions on the correlation between household income and residential location and the correlation between household income and car ownership. Second, the current model incorporates two modes of intraurban transportation that differ in speed and costs: bus and car. The bus in the model serves as a proxy for all forms of public transportation that are cheaper and slower than the automobile. Finally, unlike the standard model, which assumes that commuting is the only form of intraurban travel, this study also allows for leisure travel. All noncommuting travel such as travel for shopping, outdoor activities, and visiting friends or relatives is considered as leisure travel in the model.

11 Source: Raff and Trajtenberg (1997). Their Table 2.9 shows the quality-adjusted price index for automobiles (in current dollars) over the period 1906-1983. They also report that the mean price of a car in 1906 was 52,640 dollars (in 1993 dollars). Using these and the CPI, one can compute the quality-adjusted prices (in constant 2000 dollars) for the period 1906-1983.

12 The time period in question justifies the use of monocentric city model. As mentioned in Section 1.1, the majority of employment was located in the central cities over the period 1910-1970. 


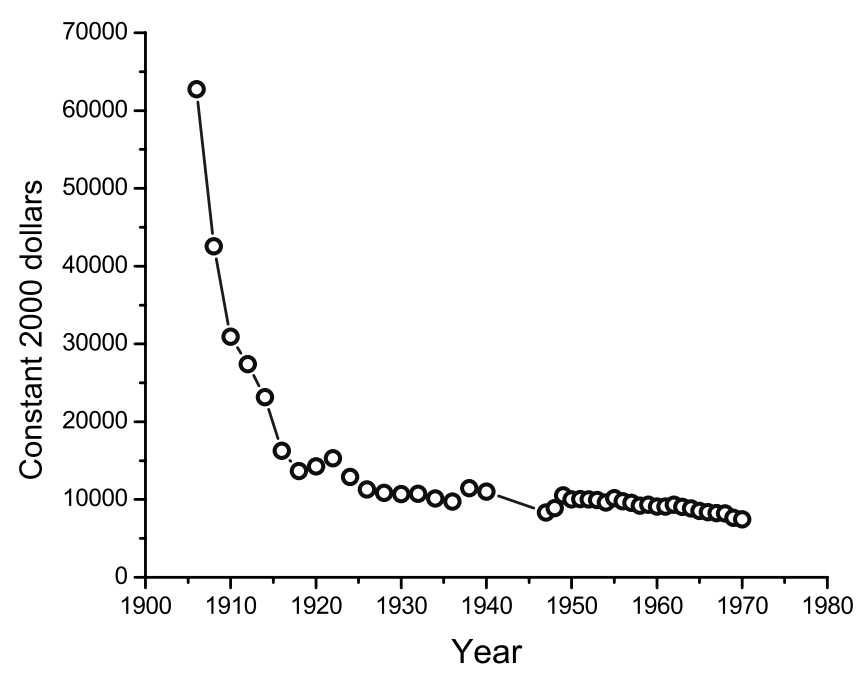

SOURCE: See footnote 11.

Figure 2

Price of New Automobiles: 1906-1970

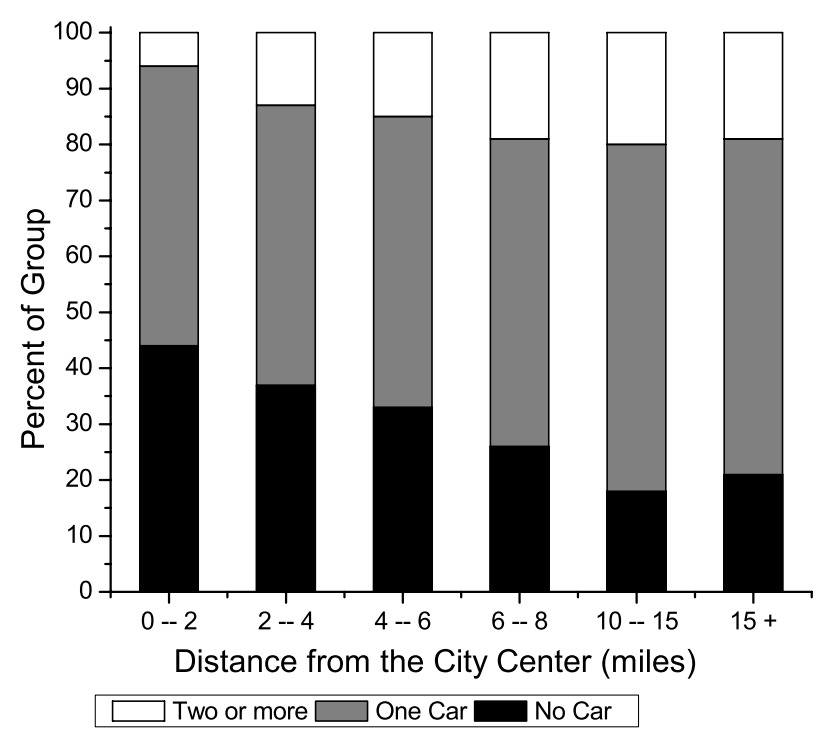

SourCE: Survey of Consumer Finances, University of Michigan.

FIGURE 3

CAR OWNERSHIP IN 1962 BY DISTANCE FROM CENTER OF CENTRAL CITY

Households in the model economy have to choose a residential location and a mode of transportation. When agents make their location choices, they take into consideration three factors: the cost of commuting, the cost of housing, and the benefits of leisure travel. The desire to save on commuting costs induces the households to live closer to the employment center. This in turn generates a large demand for housing around the center and bids up rents. In the standard model, optimal location choice involves a balance between these two forces. In this study, however, the location decision is also affected by a third factor: the benefits of leisure travel. Empirical evidence as well as everyday experience shows that the density of stores, restaurants, and people is higher in the central cities than in the surrounding suburbs. Hence, when comparing to a suburban household, a household living close to the city center does not 
have to travel as far from home for shopping, dining, and other leisure activities. This observation is captured in the model by allowing the benefit of traveling a fixed distance for leisure to be decreasing in the distance from the city center. This provides an additional incentive for city dwellers to stay close to the center.

In the model, the choices of residential location and whether or not to purchase a car are closely related. By owning a car, one can reduce the time costs of both commuting and leisure travel. This induces households to spread to neighboring suburbs and enjoy larger living spaces. But not everyone will choose to own a car. The price of a car serves as a fixed cost that screens out those with low incomes. As incomes rise and car prices decline over time, more households adopt the automobile and this promotes suburbanization. ${ }^{13}$ Other features of the model that impact the rate of automobile adoption and suburbanization are changes in the costs of traveling by car relative to bus and changes in the size of the urban population. The importance of these factors in generating suburbanization is assessed quantitatively as discussed below.

The model generates some interesting theoretical predictions on the spatial distribution of urban populations. First, the model predicts a positive relationship between household income and distance from the city center. In other words, poorer households in the model economy tend to locate closer to the city center whereas wealthier households choose locations further away. This kind of spatial pattern is consistent with empirical evidence. For example, according to the 1960 census, the median income of households living in the central cities was 5,940 dollars compared to 6,707 dollars for suburban households. ${ }^{14}$ It is also well documented that a disproportionately large fraction of poor households in the United States live close to the city center (Mills and Lubuele, 1997). Second, the model predicts that bus users and car owners are segregated in terms of both income and residential location. More specifically, there exists a unique threshold income level below which agents would choose to be bus users and live close to the city center and above that agents would choose to be car owners and locate further away. Although such severe segregation is not observed in the real world, this result suggests a close connection between public transportation usage and central city poverty that is supported by empirical evidence. In a recent study, Glaeser et al. (2008) argue that better access to public transportation in the central cities is an important factor in keeping low-income families in such locations.

The model is solved numerically and calibrated to match data on car ownership, suburbanization over the period 1910-1940, as well as travel times and commuting costs. Potential driving forces of suburbanization and increasing car ownership in the model are rising real wages, declining automobile prices, an increase in the overall cost of using public transportation relative to using an automobile, and urban population growth, all of which are taken either directly from the data or indirectly through the calibration procedure. According to the model, the growth in urban population over the 1910-1970 period had only a small impact on car-ownership rates and suburbanization. The dominant driver of suburbanization during the 1910-1950 period was declining prices of automobiles, followed by reductions in the time and fixed costs of traveling by car. However, from 1950 to 1970, rising real wages played the dominant role, followed by the decrease in automobile prices. The impact of changes in the time and fixed costs of traveling using public transportation was small. Under the baseline calibration, the model is able to account for $60 \%$ of postwar suburbanization. The results support the argument that basic economic forces such as rising incomes and falling transportation costs were the primary drivers of suburbanization in the United States in both the prewar and postwar periods. In addition, the results suggest that factors that are not considered in the model, such as "white flight" and

13 Car price is assumed to be the only cost of purchasing a car. In particular, interest costs associated with credit financing are abstracted from. This abstraction is justified on two grounds. First, empirical evidence shows that most automobile purchasers did not use credit before 1950. Hence interest costs were a small fraction of ownership costs in the early years. Second, using existing data on the finance rate and the maturity of automobile credit for the period $1950-1970$, it is estimated that interest costs are less than $10 \%$ of the price of a car. The actual percentage cannot be determined due to insufficient data. Details of these data are available upon request.

14 Data on household income by residence are available only as far back as 1960 . 


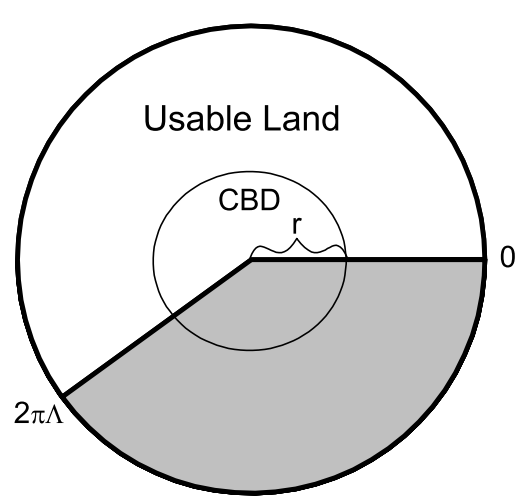

Figure 4

SCHEMATIC OF MODEL CITY

central city disamenities, may be important in explaining postwar suburbanization. These results are thus consistent with Boustan (2007), who estimates that "white flight" can explain about $20 \%$ of the suburbanization trend between 1940 and $1970 .^{15}$

This article is closest in spirit to LeRoy and Sonstelie (1983). These authors extend the standard monocentric city model by allowing for two modes of transportation. In their analysis, they provide conditions under which the rich and the poor would choose different modes and live in different parts of the city. Unlike this study, LeRoy and Sonstelie did not explore the quantitative implications of their model. They also assume that commuting is the only use of cars. Another paper that studies suburbanization by extending the standard model is Baum-Snow (2007b). He extends the model by adding highways, which increase the speed of commuting. Similar to the standard model, the analysis in his paper is based on a homogeneous population. It is thus unable to explain the correlation between household income and residential location observed in the data.

The rest of this article is organized as follows. Section 2 presents the model and the theoretical results. Section 3 discusses the calibration procedure. Section 4 presents the baseline results and the counterfactual experiments. This is followed by some concluding remarks in Section 5 .

\section{THE MODEL}

2.1. The Environment. Consider a geographical region $\mathcal{P}$ located on the Cartesian plane $\mathbb{R}^{2}$. Because of the existence of waterways and other undevelopable geographical areas, realworld cities are rarely full circles. In order to capture this fact, it is assumed that only a portion of $\mathcal{P}$ is usable land that can consist of commercial, residential, and agricultural areas. At each distance $s$ from the origin, a constant fraction $\Lambda \in(0,1)$ of land is assumed to be usable. Let $\mathcal{C}(s)$ denote the set of usable land at distance $s$ from the origin. This can be represented formally using polar coordinates. Let $v \in[0,2 \pi]$ be a polar angle. Then $\mathcal{C}(s)$ is defined as

$$
\mathcal{C}(s) \equiv\{(s, v): v \in[0,2 \pi \Lambda]\}
$$

All usable land in $\mathcal{P}$ is identical and is uniformly distributed.

The model city is located on the usable part of $\mathcal{P}$. An aerial map of the city is shown in Figure 4 . The size of the city is determined endogenously. The city has a single employment

15 Baum-Snow (2007a) is also closely related to this study. For two reasons, however, it is difficult to compare the quantitative results of the studies. First, Baum-Snow considers the effects of highway construction by comparing the extent of suburbanization between two time periods: 1950 and 1990. It is not clear from his study how much highway construction contributed to suburbanization during the 1950-1970 period. Second, instead of using average population density gradient, Baum-Snow uses the share of the metropolitan population living in the central cities to measure the extent of suburbanization. 
center called the central business district (CBD). All production activities take place in the CBD. The $\mathrm{CBD}$ is centered at the origin and is represented by $\mathcal{B} \equiv\{\mathcal{C}(s): s \in[0, r]\}$. The radius $r$ is set to $(2 \pi \Lambda)^{-1}$ so that the total supply of usable land on the boundary of the CBD is normalized to one. All usable land outside the CBD is rented for either residential or agricultural purposes in a competitive market. ${ }^{16}$ At each distance $x$ from the boundary of the CBD the total supply of usable land, that is, land in $\mathcal{C}(x+r)$, is given by $2 \pi \Lambda(r+x)$. Each unit of land in $\mathcal{C}(x+r)$ is the same and, therefore, is let for the same rent $q(x)$. All rent is collected by a group of absentee landlords.

The city is part of a large economy in which there are two types of commodities: consumption goods and automobiles. Both commodities are produced and traded within the city and in the larger economy. Their prices are determined in the latter and taken as given by the inhabitants of the city. There is a continuum of agents of mass $N>0$ living inside the city. Each agent is characterized by an ability $\lambda \in\left[\lambda_{\min }, \lambda_{\max }\right]$. The ability distribution function is given by $F(\lambda)$, with $F\left(\lambda_{\min }\right)=0$ and $F\left(\lambda_{\max }\right)=N$. All agents have to decide on a residential location that then serves as the point of departure for all travel inside the city. There are two types of travel: commuting and leisure travel. Since all the employment is located in the city center, all workers have to commute between their residential locations and the boundary of the CBD for work. Travel within the CBD is assumed to be negligible. All other traveling is classified as leisure travel. For any agent who lives in $\mathcal{C}(x+r)$, the benefits of traveling a total distance $z$ for leisure purpose is captured by

$$
\phi(x, z)=e^{-\eta x} z^{\theta}, \quad \text { with } \theta \in(0,1), \eta>0 .
$$

This specification satisfies the following assumptions regarding leisure travel. First, the benefit of leisure travel is increasing in the total distance traveled since $\partial \phi(x, z) / \partial z>0$ for all $x, z>0$. Intuitively, one can enjoy a wider variety of stores and recreational activities and visit more friends and relatives by traveling a longer distance or taking more trips. However, there are diminishing returns to leisure travel since $0<\theta<1$ implies that $\partial^{2} \phi(x, z) / \partial z^{2}<0$ for all $x, z>$ 0 . Second, for any given value of $z>0$, the function $\phi(x, z)$ is strictly decreasing in $x$. This feature is intended to capture the following idea: Since both businesses and people are more dispersed in the suburban areas, a person who lives in the suburb (or further from the CBD) would have to travel a longer distance than one who lives in the city (or closer to the CBD) in order to reap the same benefit from a leisure trip.

Each agent derives utility from consumption $(c)$, residential land services $(l)$, and the benefits of leisure travel. ${ }^{17}$ The utility function is given by

$$
U(c, l, z, x)=\alpha \ln c+\zeta \ln l+(1-\alpha-\zeta) \ln \phi(x, z),
$$

where $\alpha, \zeta \in(0,1)$. Each agent is endowed with one unit of time, which can be divided between market work, commuting, and leisure travel.

There are two modes of transportation inside the city: bus and car. Bus services are available throughout the entire city. These services are publicly owned and operated. On the other hand, any agent who wants to travel by car has to buy one at price $p_{c}$ and become a car owner. ${ }^{18}$ An agent's total transportation cost is divided into two components: a time cost and a fixed cost. If the agent chooses to travel a distance $x$ by bus, then the total transportation cost is given by

16 The agricultural sector is not explicitly modeled here, nor do agents have any demand for agricultural products. The agricultural sector exists only to serve as an alternative land user.

17 "Land" and "housing" are interchangeable in this article. This implicitly assumes that the supply of housing is equivalent to the supply of land and is thus exogenously given. It also implies that the supply of housing is uniformly distributed throughout the urban area.

18 No differentiation is made between used and new cars. The reasons for this abstraction are mentioned in footnote 27 


$$
t(w \lambda, x)=\tau_{b}(x) w \lambda+\gamma_{b}
$$

where $w>0$ is an exogenously given wage rate for an effective unit of labor, $\tau_{b}(x)$ is the amount of time needed to travel the distance $x$ by bus, and $\gamma_{b}>0$ is the fixed cost of using the bus. The function $\tau_{b}(x)$ is assumed to be linear, that is,

$$
\tau_{b}(x)=\psi_{b} x, \quad \text { with } \psi_{b}>0
$$

The parameter $\psi_{b}$ is the time required to travel a unit distance by bus. If the same agent chooses to travel by car, then the total transportation cost is

$$
\tau(w \lambda, x)=\tau_{c}(x) w \lambda+\gamma_{c},
$$

where $\tau_{c}(x)$ is the amount of time needed to travel the distance $x$ by car, and $\gamma_{c}>0$ is the fixed cost of using a car. The function $\tau_{c}(x)$ is given by ${ }^{19}$

$$
\tau_{c}(x)=\psi_{c} x, \quad \text { with } \psi_{c}>0
$$

The parameter $\psi_{c}$ is the time required to travel a unit distance by car. Notice that, conditional on the mode of transportation, it is more costly for high-ability agents to travel than for low-ability agents.

Compared to taking the bus, the fixed cost of traveling by car is assumed to be higher, or

$$
\gamma_{c}+p_{c}>\gamma_{b}
$$

However, it takes more time for bus users to travel the same distance as car owners, that is,

$$
\tau_{c}(x)<\tau_{b}(x), \quad \text { for all } x>0,
$$

or equivalently, $\psi_{c}<\psi_{b}$.

2.2. Bus User's Problem. Consider an agent with ability $\lambda$ who chooses to do all his traveling by bus. Taking the rent function $q(\cdot)$ and the market wage rate $w$ as given, the agent chooses his consumption of goods $(c)$ and land services $(l)$, time allocated to market work $(m)$, the distance between his residence and the boundary of the CBD $(x)$, and the total distance to travel for leisure purposes $(z)$ so as to maximize his utility subject to his budget constraint and time constraint. Formally, the agent's problem is given by

$$
V^{b}(\lambda)=\max _{c, l, z, x, m}\{\alpha \ln c+\zeta \ln l+(1-\alpha-\zeta) \ln \phi(x, z)\}
$$

subject to

$$
\begin{gathered}
c+q(x) l+\gamma_{b}=w \lambda m, \\
m+\tau_{b}(z)+\tau_{b}(x)=1, \\
z, x \geq 0,
\end{gathered}
$$

19 All the theoretical results in this article remain valid when the time cost functions $\tau_{b}(x)$ and $\tau_{c}(x)$ are generalized to become $\tau_{b}(x)=\psi_{b} x^{\sigma}$ and $\tau_{c}(x)=\psi_{c} x^{\sigma}$, with $\psi_{b}>0, \psi_{c}>0$ and $\sigma>0$. A complete set of proofs is available from the authors upon request. 


$$
c \geq 0, \quad l \geq 0, \quad m \in[0,1]
$$

Equations (6) and (7) are the budget constraint and the time constraint, respectively.

The problem (P1) can be solved in two steps. First, conditional on any distance $x \geq 0$ such that $w \lambda\left[1-\tau_{b}(x)\right] \geq \gamma_{b}$, the optimal expenditures on consumption goods and land and the optimal amount of time spent on leisure travel are determined by ${ }^{20}$

$$
\begin{gathered}
c_{b}(\lambda, x)=\tilde{\alpha}\left[w \lambda\left(1-\tau_{b}(x)\right)-\gamma_{b}\right], \\
q(x) l_{b}(\lambda, x)=\tilde{\zeta}\left[w \lambda\left(1-\tau_{b}(x)\right)-\gamma_{b}\right],
\end{gathered}
$$

and

$$
w \lambda \tau_{b}\left(z_{b}(\lambda, x)\right)=(1-\tilde{\alpha}-\widetilde{\zeta})\left[w \lambda\left(1-\tau_{b}(x)\right)-\gamma_{b}\right]
$$

where $\widetilde{\alpha} \equiv \alpha /[\alpha+\zeta+(1-\alpha-\zeta) \theta]$ and $\tilde{\zeta}=\zeta \widetilde{\alpha} / \alpha$

The second step is to determine the optimal distance from the CBD. Let $W^{b}(\lambda, x)$ be the maximum utility that a bus user with ability $\lambda$ can attain by choosing a location at distance $x$. This can be obtained by substituting $c_{b}(\lambda, x), l_{b}(\lambda, x)$, and $z_{b}(\lambda, x)$ into the utility function in (P1). The feasible set of $x$ is given by

$$
\mathcal{D}(\lambda)=\left\{x \in \mathbb{R}_{+}: w \lambda\left[1-\tau_{b}(x)\right] \geq \gamma_{b}\right\} .
$$

The agent's optimal location choice, represented by $x_{b}(\lambda)$, is defined as ${ }^{21}$

$$
x_{b}(\lambda) \equiv \arg \max _{x \in \mathcal{D}(\lambda)}\left\{W^{b}(\lambda, x)\right\}
$$

The indirect utility function of a bus user with ability $\lambda$ is then given by

$$
V^{b}(\lambda) \equiv W^{b}\left[\lambda, x_{b}(\lambda)\right]
$$

To illustrate the costs and benefits behind the choice of $x$, consider an agent with ability $\lambda$ who is comparing between two locations: one at distance $x_{1} \geq 0$, the other at distance $x_{2}>x_{1}$. The differences in $W^{b}(\lambda, x)$ between these two locations can be decomposed into three parts

$$
\begin{aligned}
W^{b}\left(\lambda, x_{2}\right)-W^{b}\left(\lambda, x_{1}\right)= & \tilde{\theta} \ln \left\{\frac{w \lambda\left[1-\tau_{b}\left(x_{2}\right)\right]-\gamma_{b}}{w \lambda\left[1-\tau_{b}\left(x_{1}\right)\right]-\gamma_{b}}\right\} \\
& -(1-\alpha-\zeta) \eta\left(x_{2}-x_{1}\right)-\zeta \ln \frac{q\left(x_{2}\right)}{q\left(x_{1}\right)}
\end{aligned}
$$

20 The use of $\log$ arithmic utility ensures that $c=l=z=0$ is never optimal. This also means it is never optimal to have $m=0$. The set of constraints can then be reduced to

$$
c+q(x) l+w \lambda \tau_{b}(z)=w \lambda\left[1-\tau_{b}(x)\right]-\gamma_{b},
$$

and $x \geq 0$. Obviously it is never optimal to have $w \lambda\left[1-\tau_{b}(x)\right]<\gamma_{b}$.

21 Since $\tau_{b}(\cdot)$ is continuous and strictly increasing, the feasible set $\mathcal{D}(\lambda)$ is a closed interval on the positive real line. Since $W^{b}(\lambda, x)$ is continuous in $x$, the optimal solution correspondence $x_{b}(\lambda)$ is non-empty, compact-valued, and upper hemicontinuous in $\lambda$. In the following analysis, it is assumed that a unique solution for (P2) exists for all bus users with ability $\lambda \in\left[\lambda_{\min }, \lambda_{\max }\right]$. In other words, $x_{b}(\lambda)$ is assumed to be a single-valued function for all $\lambda \in\left[\lambda_{\min }, \lambda_{\max }\right]$. If $x_{b}(\lambda)$ is single-valued and upper hemicontinuous, then it is a continuous function. The same uniqueness assumption is made for $x_{c}(\lambda)$ defined in the car owner's problem. In the numerical analysis, caution is taken to ensure that the uniqueness assumption is fulfilled. 
where $\tilde{\theta} \equiv \alpha+\zeta+(1-\alpha-\zeta) \theta$. By choosing to locate at $x_{2}$ and hence live that much further away from the $\mathrm{CBD}$, the agent faces an increase in transportation costs and hence a reduction in net income $\left\{w \lambda\left[1-\tau_{b}(x)\right]-\gamma_{b}\right\}$. In response, the agent reduces consumption in goods and housing and the time spent on leisure travel. The loss in utility due to these reductions is captured by the first term in (11). Moving away from the CBD would also lower the benefits of leisure travel. The loss in utility due to this is captured by the second term in (11). If these losses are not checked by a decline in land rent, then the agent would strictly prefer $x_{1}$ to $x_{2}$. In other words, if land rents are nondecreasing in distance from the CBD, then all the bus users would choose to live as close to the CBD as possible. In this case, the optimal location choice is $x_{b}(\lambda)=0$ for all $\lambda$. On the contrary, if an agent optimally chooses to locate at distance $x>0$, then it must be the case that $q(x)<q(0)$, so that the costs of moving away from the CBD are compensated by a reduction in rent.

One implication of this model is that, conditional on using the same mode of transportation, high-ability agents choose to live further away from the CBD than low-ability agents. In other words, the optimal location function $x_{b}(\lambda)$ is an increasing function. This can be seen by considering (11) again. As explained above, the first two terms in (11) capture the losses in utility when an agent moves away from the CBD, whereas the last term captures the gains in utility by doing so. Among these three terms, only the first one depends on $\lambda$. In particular, this term is strictly increasing in $\lambda .^{22}$ When an agent moves further away from the CBD, less time is allocated to market work, and hence net income decreases. But the relative size of this reduction is not identical for all agents. Instead, it is smaller for high-ability agents than for low-ability ones. Thus, it is less costly for high-ability agents to move away from the CBD. Consequently, bus users with high ability would choose to live further away from the CBD than those with low ability. This result is summarized in Lemma 1. All the proofs can be found in the Appendix.

Lemma 1. The optimal location choice function for bus users, $x_{b}(\lambda)$, is increasing over the range $\left[\lambda_{\min }, \lambda_{\max }\right]$.

2.3. Car Owner's Problem. If an agent with ability $\lambda$ chooses to own a car, then he solves the following problem, taking the rent function $q(\cdot)$, the market wage rate $w$, and the price of cars $p_{c}$ as given:

$$
V^{c}(\lambda)=\max _{c, l, z, x, m}\{\alpha \ln c+\zeta \ln l+(1-\alpha-\zeta) \ln \phi(x, z)\}
$$

subject to

$$
\begin{gathered}
c+q(x) l+\gamma_{c}+p_{c}=w \lambda m, \\
m+\tau_{c}(z)+\tau_{c}(x)=1, \\
z, x \geq 0, \\
c \geq 0, \quad l \geq 0, \quad m \in[0,1] .
\end{gathered}
$$

Conditional on any distance $x \geq 0$ such that $w \lambda\left[1-\tau_{c}(x)\right] \geq \gamma_{c}+p_{c}$, the optimal expenditures on consumption goods and land and the optimal amount of time spent on leisure travel are determined by

$$
c_{c}(\lambda, x)=\widetilde{\alpha}\left[w \lambda\left(1-\tau_{c}(x)\right)-\left(\gamma_{c}+p_{c}\right)\right]
$$

22 Mathematically, this implies that the function $W^{b}(\lambda, x)$ satisfies strictly increasing differences in $(\lambda, x)$. This property is used in the proof of Lemma 1. The ideas of the proof are similar to those described in Sundaram (1996, Section 10.2). 


$$
q(x) l_{c}(\lambda, x)=\tilde{\zeta}\left[w \lambda\left(1-\tau_{c}(x)\right)-\left(\gamma_{c}+p_{c}\right)\right]
$$

and

$$
w \lambda \tau_{c}\left(z_{c}(\lambda, x)\right)=(1-\widetilde{\alpha}-\widetilde{\zeta})\left[w \lambda\left(1-\tau_{c}(x)\right)-\left(\gamma_{c}+p_{c}\right)\right]
$$

Let $W^{c}(\lambda, x)$ be the maximum utility that a car owner with ability $\lambda$ can attain by choosing a location at distance $x$. The agent then chooses an optimal distance from the feasible set

$$
\left\{x \in \mathbb{R}_{+}: w \lambda\left[1-\tau_{c}(x)\right] \geq \gamma_{c}+p_{c}\right\}
$$

so as to maximize $W^{c}(\lambda, x)$. Let $x_{c}(\lambda)$ be the unique solution for this problem. The indirect utility function for a car owner with ability $\lambda$ is then given by $V^{c}(\lambda) \equiv W^{c}\left[\lambda, x_{c}(\lambda)\right]$.

Using the same proof as in Lemma 1 , one can show that $x_{c}(\lambda)$ is an increasing function. This, together with Lemma 1, implies that conditional on choosing the same mode of transportation, high-ability agents will choose to live further from the CBD than low-ability agents.

LEMMA 2. The optimal location choice function for car users, $x_{c}(\lambda)$, is increasing over the range $\left[\lambda_{\min }, \lambda_{\max }\right]$.

2.4. Car Ownership and Location Decisions. An agent with ability $\lambda$ will choose to own a car if and only if $V^{c}(\lambda)>V^{b}(\lambda)$. The car-ownership decision can be summarized by

$$
\Omega(\lambda)= \begin{cases}1, & \text { if } V^{c}(\lambda)>V^{b}(\lambda), \\ 0, & \text { if } V^{c}(\lambda) \leq V^{b}(\lambda),\end{cases}
$$

for $\lambda \in\left[\lambda_{\min }, \lambda_{\max }\right]$. Define a critical ability level $\bar{\lambda}$ such that $V^{c}(\bar{\lambda})=V^{b}(\bar{\lambda})$. An agent with ability $\bar{\lambda}$ is indifferent between traveling by bus and purchasing a car for travel.

Suppose at least one critical ability level exists so that there are both car owners and bus users in the city. The two groups of agents are said to be separated in terms of location if there exists $\bar{x}>0$ such that one group of agents would live further than distance $\bar{x}$ from the boundary of the CBD whereas the other group would live closer to the boundary than $\bar{x}$. In the current framework, assumptions (4) and (5) are sufficient to ensure that car owners and bus users are separated in terms of location. This result is summarized in Proposition 1.

Proposition 1. Suppose a critical ability level $\bar{\lambda}$ exists. Then there exists a unique pair of distances $(\bar{x}, \tilde{x}), \tilde{x}>\bar{x} \geq 0$, such that (i) all bus users would live no further than distance $\bar{x}$ from the boundary of the $C B D$ and (ii) all car owners would live further than distance $\bar{x}$ but no further than $\tilde{x}$.

2.5. Competitive Equilibrium. In this context, a competitive equilibrium refers to a situation in which (i) competitive land markets in every location clear and (ii) neither the agents nor the landlords have any incentive to change their decisions. The following description focuses on an economy in which both car owners and bus users exist. In the subsequent discussions, it is shown that at most one critical ability level $\bar{\lambda}$ exists in equilibrium.

2.5.1. Equilibrium city structure. By Proposition 1, all agents will reside within distance $\tilde{x}$ from the boundary of the CBD. In other words, the city can be represented by

$$
\mathbf{C}=\{\mathcal{C}(s): s \in[0, r+\widetilde{x}]\}
$$


which includes the $\mathrm{CBD} \mathcal{B}=\{\mathcal{C}(s): s \in[0, r]\}$. In equilibrium, no usable land in $\mathcal{P}$ is left vacant. Therefore, all land in $\mathbf{C} \backslash \mathcal{B}$ must be utilized either for residence or for agriculture. If this is not true then any rational landlord would lower the rent at the empty spot so as to induce someone to move in. In fact, all land in $\mathbf{C} \backslash \mathcal{B}$ must be occupied by residence. This will become clear later on.

Since all agents are settled within the boundary of $\mathbf{C}$, land beyond the city boundary is used for agriculture. Let $q_{\mathrm{A}}$ be the agricultural rent. The equilibrium rent function must satisfy

$$
q(\tilde{x})=q_{\mathrm{A}}
$$

The argument is as follows. First note that if $q(\tilde{x})<q_{\mathrm{A}}$, then any rational landlord would choose to rent out the land at distance $\tilde{x}$ to agricultural users. Suppose instead that $q(\widetilde{x})>q_{\mathrm{A}}$. In this case, agents living at distance $\tilde{x}$ would be strictly better off by moving to a location at distance $\widetilde{x}+\varepsilon$, with $\varepsilon>0$. If $\varepsilon$ is sufficiently small, then the transportation costs and the benefits of leisure travel would only be marginally affected but would be compensated for by a reduction in rent of $q(\tilde{x})-q_{\mathrm{A}}$. This creates an incentive for those living at distance $\tilde{x}$ to move and hence cannot be an equilibrium.

In equilibrium, all land in $\mathbf{C} \backslash \mathcal{B}$ is used for residential purposes. In order to see this, first define $\mathcal{R}\left(x_{1}, x_{2}\right)$, for any $\tilde{x} \geq x_{2}>x_{1} \geq 0$, to be the set of usable land further than distance $x_{1}$ from the boundary of the CBD but no further than distance $x_{2}$, that is,

$$
\mathcal{R}\left(x_{1}, x_{2}\right) \equiv\left\{\mathcal{C}(s): x_{1}+r \leq s \leq x_{2}+r\right\}
$$

Now suppose, to the contrary, that there exists some region $\mathcal{R}\left(x_{1}, x_{2}\right)$ in $\mathbf{C} \backslash \mathcal{B}$ that is used for agriculture, whereas all other land in $\mathbf{C} \backslash \mathcal{B}$ is used for residential purposes. By the above argument, it must be the case that $q\left(x_{1}\right)=q_{\mathrm{A}}$. Since it is never optimal for any landlord to rent the land for less than $q_{\mathrm{A}}$, the rent charged to residents at distance $x$ in $\left(x_{2}, \tilde{x}\right]$ must be $q(x) \geq q_{\mathrm{A}}$. This means any agent who chooses to locate at distance $x$ in $\left(x_{2}, \tilde{x}\right]$ would be strictly better off by moving to a location at distance $x_{1}$ where the rent is the same or lower but the transportation costs are strictly lower and the benefits of leisure trips are strictly higher. This creates an incentive for those who live in $\left(x_{2}, \tilde{x}\right]$ to move. Hence this cannot be an equilibrium.

2.5.2. Car ownership and location. In equilibrium, if a critical ability level $\bar{\lambda}$ exists, then it must be unique. In addition, all agents with ability higher than $\bar{\lambda}$ will choose to own a car whereas those with ability lower than $\bar{\lambda}$ will choose to use the bus. These results are summarized in Proposition 2.

\section{Proposition 2. The following must be true in equilibrium:}

(i) If a critical ability level $\bar{\lambda}$ exists, then it must be unique. In addition $x_{b}(\bar{\lambda})=x_{c}(\bar{\lambda})=\bar{x}$.

(ii) All agents with $\lambda>(<) \bar{\lambda}$ would choose to be car owners (bus users).

For any $\lambda \in\left[\lambda_{\min }, \lambda_{\max }\right]$, define

$$
x(\lambda)=x_{b}(\lambda)[1-\Omega(\lambda)]+x_{c}(\lambda) \Omega(\lambda) .
$$

The function $x(\lambda)$ summarizes the optimal location choice for every agent in the city. The next proposition establishes that in equilibrium $x(\lambda)$ is continuous and strictly increasing. Strict monotonicity of $x(\lambda)$ means that there is a one-to-one relationship between distance and ability. The city boundary is then determined by

$$
\tilde{x}=x\left(\lambda_{\max }\right)=x_{c}\left(\lambda_{\max }\right) .
$$


Proposition 3. In equilibrium, $x(\lambda)$ is continuous and strictly increasing over the range $\left[\lambda_{\min }, \lambda_{\max }\right]$.

2.5.3. Equilibrium rent. Given a continuous distribution of abilities and continuous transportation cost functions for both car owners and bus users, it is immediate to see that the equilibrium rent function $q(x)$ must be continuous over the region where there are bus users or car owners only. This means $q(x)$ is continuous for any $x$ greater than or lower than $\bar{x}$. Suppose $q(x)$ is discontinuous at $\bar{x}$ and

$$
q(\bar{x})>\lim _{x \rightarrow \bar{x}^{+}} q(x) .
$$

Given the gap in rent at distance $\bar{x}$, any agent with critical ability level $\bar{\lambda}$ can benefit by moving slightly further out to a new location at distance $\bar{x}+\varepsilon>\bar{x}$. Since $\varepsilon$ can be made arbitrarily small, a new location can always be found such that the costs of moving there are over compensated for by the reduction in rent. This creates an incentive to move and hence cannot be a equilibrium. By a similar argument, one can rule out the case with $\lim _{x \rightarrow \bar{x}^{-}} q(x)>q(\bar{x})$. Hence $q(x)$ is continuous over $\mathbf{C}$.

2.5.4. Population distribution. For any distance $y$ in $[0, \tilde{x}]$, let $\mathcal{A}(y) \equiv\{\mathcal{C}(s): r \leq s \leq y+r\}$ be the set of usable land that is no further than $y$ from the boundary of the CBD. The population distribution function, $P(y)$, specifies the size of population living in the area $\mathcal{A}(y)$ for any $y$ in $[0, \tilde{x}]$. The population distribution function can be constructed using the optimal location choice function $x(\lambda)$, and the ability distribution $F(\lambda)$. To see this, first define the set $\Gamma(y)$ by

$$
\Gamma(y)=\left\{\lambda \in\left[\lambda_{\min }, \lambda_{\max }\right]: x(\lambda) \leq y\right\},
$$

for any $y$ in $[0, \widetilde{x}]$. This set specifies the abilities of agents who optimally choose to live in $\mathcal{A}(y)$. Then the population distribution function can be expressed as

$$
P(y)=\int_{\Gamma(y)} d F(\lambda), \quad \text { for all } y \in[0, \tilde{x}]
$$

with $P(0)=0$ and $P(\widetilde{x})=N$.

2.5.5. Competitive land markets. In equilibrium, the demand for land by an agent with ability $\lambda$ is given by

$$
l(\lambda)=l_{b}\left[x_{b}(\lambda), \lambda\right][1-\Omega(\lambda)]+l_{c}\left[x_{c}(\lambda), \lambda\right] \Omega(\lambda),
$$

where $\Omega(\lambda)$ is defined in (15). For any distance $y$ in $[0, \tilde{x}]$, the total supply of land in area $\mathcal{A}(y)$ is given by

$$
\Lambda \int_{0}^{y} 2 \pi(r+x) d x=2 \pi \Lambda r y+\Lambda \pi y^{2}
$$

where $2 \pi \Lambda r=1$ is the total supply of land on the boundary of the CBD. The land markets in area $\mathcal{A}(y)$ clear if the total demand for land equals the total supply, or equivalently,

$$
\int_{\Gamma(y)} l(\lambda) d F(\lambda)=y+\Lambda \pi y^{2}
$$


2.5.6. Definition of equilibrium. Given an ability distribution $F(\lambda)$, a competitive equilibrium of this economy consists of a set of decision rules for car owners $\left\{c_{c}(\lambda), l_{c}(\lambda), z_{c}(\lambda), x_{c}(\lambda)\right\}$, a set of decision rules for bus users $\left\{c_{b}(\lambda), l_{b}(\lambda), z_{b}(\lambda), x_{b}(\lambda)\right\}$, a car-ownership decision rule $\Omega(\lambda)$, an optimal location choice function $x(\lambda)$, a population distribution function $P(x)$, and a rent function $q(x)$ such that

1. Given the rent function $q(x)$, for each bus user with ability $\lambda$, the allocation $\left\{c_{b}(\lambda), l_{b},(\lambda) z_{b}(\lambda), x_{b}(\lambda)\right\}$ solves (P1) and for each car owner with ability $\lambda$ the allocation $\left\{c_{c}(\lambda) l_{c}(\lambda), z_{c}(\lambda), x_{c}(\lambda)\right\}$ solves $(\mathrm{P} 3)$.

2. The car-ownership decision rule, $\Omega(\lambda)$, is given by (15).

3. The optimal location choice function, $x(\lambda)$, is defined by (17).

4. The population distribution function, $P(x)$, is given by (18).

5. The land market at every location clears, or (19) holds for all $y \in[0, \tilde{x}]$ and the rent at the boundary of the city equals the agricultural rent, or (16) holds.

2.5.7. Characterization of equilibrium. The equilibrium defined above is made up of three parts: the bus user's problem, the car owner's problem, and a critical ability level $\bar{\lambda}$ that connects the two. In the quantitative analysis, attention will be restricted to a class of equilibria in which the optimal location choice functions for bus users and car owners are differentiable. The bus user's problem is then characterized by a pair of differential equations:

$$
x_{b}^{\prime}(\lambda)=\frac{w \lambda f(\lambda)}{1+2 \pi \Lambda x_{b}(\lambda)} \frac{\tilde{\zeta}}{\tilde{q}(\lambda)}\left[1-\psi_{b} x_{b}(\lambda)-\frac{\gamma_{b}}{w \lambda}\right]
$$

and

$$
\widetilde{q}^{\prime}(\lambda)=\frac{-w \lambda f(\lambda)}{1+2 \pi \Lambda x_{b}(\lambda)}\left\{\psi_{b}+\frac{(1-\alpha-\zeta) \eta}{\widetilde{\theta}}\left[1-\psi_{b} x_{b}(\lambda)-\frac{\gamma_{b}}{w \lambda}\right]\right\}
$$

where $\widetilde{q}(\lambda) \equiv q\left[x_{b}(\lambda)\right]$ for $\lambda \in\left[\lambda_{\min }, \bar{\lambda}\right]$. The mathematical derivations of (20) and (21) are shown in the Appendix. The optimal location function for bus users must also satisfy the boundary conditions $x_{b}\left(\lambda_{\min }\right)=0$ and $x_{b}(\bar{\lambda})=\bar{x}$.

Similarly, the car owner's problem is characterized by

$$
x_{c}^{\prime}(\lambda)=\frac{w \lambda f(\lambda)}{1+2 \pi \Lambda x_{c}(\lambda)} \frac{\tilde{\zeta}}{\widetilde{q}(\lambda)}\left[1-\psi_{c} x_{c}(\lambda)-\frac{\gamma_{c}+p_{c}}{w \lambda}\right]
$$

and

$$
\tilde{q}^{\prime}(\lambda)=\frac{-w \lambda f(\lambda)}{1+2 \pi \Lambda x_{c}(\lambda)}\left\{\psi_{c}+\frac{(1-\alpha-\zeta) \eta}{\widetilde{\theta}}\left[1-\psi_{c} x_{c}(\lambda)-\frac{\left(\gamma_{c}+p_{c}\right)}{w \lambda}\right]\right\}
$$

where $\widetilde{q}(\lambda) \equiv q\left[x_{c}(\lambda)\right]$ for $\lambda \in\left[\bar{\lambda}, \lambda_{\max }\right]$. The optimal location function for car owners must satisfy the boundary condition $x_{c}(\bar{\lambda})=\bar{x}$, and the rent function that solves this system must satisfy the terminal condition $\widetilde{q}\left(\lambda_{\max }\right)=q_{\mathrm{A}}$.

Finally, the critical ability level and the corresponding location are determined by the condition $V^{b}(\bar{\lambda})=V^{c}(\bar{\lambda})$, which is equivalent to

$$
\beta-1+\left(\psi_{b}-\beta \psi_{c}\right) \bar{x}=\frac{\beta\left(\gamma_{c}+p_{c}\right)-\gamma_{b}}{w \bar{\lambda}},
$$

where $\beta \equiv\left(\psi_{b} / \psi_{c}\right)^{1-\widetilde{\alpha}-\widetilde{\zeta}}$. Details on the numerical procedure used to compute the model equilibrium can be found in the Appendix. 
TABLE 3

INDEX OF THE NUMBER OF URBAN HOUSEHOLDS IN THE 50 LARGEST CITIES IN THE UNITED STATES IN 1900

\begin{tabular}{llllllll}
\hline Year & 1910 & 1920 & 1930 & 1940 & 1950 & 1960 & 1970 \\
\hline No. of urban households & 1.00 & 1.23 & 1.65 & 1.94 & 2.43 & 2.92 & 3.46 \\
\hline
\end{tabular}

Source: See "Number of households" in the data section of the Appendix.

\section{CALIBRATION}

In order to compute the model's prediction for the contribution of automobile adoption to postwar suburbanization, a series of steady states is computed. The steady states represent an average American city for each decennial year between 1910 and 1970. Some parameters, such as the time costs of commuting, prices, population size, and the parameters governing the ability distribution will differ across the steady states. Others, such as the parameters governing preferences and the fraction of usable land, are assumed to be fixed. All parameters are pinned down using data. However, some can be set a priori whereas others must be determined by minimizing the distance between the model's predictions for a set of U.S. statistics to their counterparts from the data. The set of statistics targeted includes (i) the mean population density gradients in the decennial years from 1910 to 1940 as estimated by Edmonston (1975) and presented in Table 1, (ii) the percentage of households owning a car in the decennial years 1910, 1920, and 1950 through 1970 as shown in Table 2, and (iii) the fraction of total miles driven by car users for commuting to work in 1970. According to the National Personal Transportation Survey conducted in 1969 this fraction was $0.37 .{ }^{23}$ Once the model parameters are chosen, the model's predictions on population density gradients for the period 1950-1970 are computed and the contributions of rising car ownership to postwar suburbanization are quantified.

3.1. Parameter Values. Take the model period to be five years, which is close to the median age of passenger cars for the period 1950-1970. ${ }^{24}$ The following parameter values must be determined by the calibration exercise.

3.1.1. Usable land. The fraction of usable land in the city, $\Lambda$, is calibrated to 0.58 based on an estimate reported in Hawley (1956). For a group of 157 metropolitan areas in 1940, Hawley finds that, on average, the actual area of a city is only $58 \%$ of the area of the enclosing circle.

3.1.2. Number of households. Each agent in the model represents a single household. The number of households in each decennial year $t$ between 1910 and 1970 is denoted by $N_{t}$. Since Edmonston's estimates are for the 41 largest U.S. metropolitan areas in 1900, a similar sample is constructed in order to facilitate comparison. More specifically, a sample of the 50 most populous metropolitan areas in 1900 is considered. These cities accounted for $75 \%$ and $57 \%$ of total urban population in 1910 and 1970, respectively. Since the total number of households in these cities is not known, a proxy is constructed using the total population in these cities and the average size of nonfarm households in the United States. Details of this approach are described in the Appendix. The resulting values of $\left\{N_{1910}, \ldots, N_{1970}\right\}$ are reported in Table 3 . The number of households increases at an average annual rate of 2.1\% over the period 1910-1970.

3.1.3. Preferences. The parameters $\alpha$ and $\zeta$ determine the weights placed by households on utility from consumption, housing services, and leisure travel. In the model economy there are

23 Source: National Personal Transportation Survey: Purposes of Automobile Trips and Travel, Report 10, May 1974.

24 The average median age of passenger cars in the United States over the period 1950-1970 was 5.1 years. Source: Ward's Motor Vehicle Facts \& Figures (1999). Data for earlier years are not available. 
TABLE 4

THE EVOLUTION OF THE ABILITY DISTRIBUTION AND PRICES UNDER THE BASELINE CALIBRATION

\begin{tabular}{|c|c|c|c|c|c|c|c|c|}
\hline & Parameter & 1910 & 1920 & 1930 & 1940 & 1950 & 1960 & 1970 \\
\hline \multicolumn{9}{|l|}{ Ability distribution } \\
\hline Mean of log ability & $\mu_{t}$ & -0.0320 & -0.0320 & -0.0320 & -0.0320 & -0.0320 & -0.0255 & -0.0218 \\
\hline SD of log ability & $\sigma_{t}$ & 0.253 & 0.253 & 0.253 & 0.253 & 0.226 & 0.257 & 0.209 \\
\hline \multicolumn{9}{|l|}{ Prices } \\
\hline Mean of $w_{t} \lambda_{t}{ }^{\mathrm{a}}$ & $w_{t}$ & 65,028 & 71,518 & 78,780 & 99,342 & 131,980 & 169,475 & 211,350 \\
\hline Price of car & $p_{c, t}$ & 45,411 & 14,741 & 10,951 & 10,738 & 9,442 & 9,408 & 7,981 \\
\hline Agricultural land rent $(\$ / \text { Lot })^{\mathrm{b}}$ & $q_{A, t}$ & 36 & 24 & 16 & 26 & 56 & 75 & 98 \\
\hline
\end{tabular}

${ }^{\mathrm{a}}$ All prices are in contant 2000 dollars

b5-year rent. One lot is 12,910 square feet. (See footnote 26 for details.)

three types of consumption expenditures: consumption goods, housing services, and transportation. ${ }^{25}$ Because of the functional form for preferences, out of the first two categories, the share of expenditures on consumption goods is given by $\alpha /(\alpha+\zeta)$. Thus, the values of $\alpha$ and $\zeta$ are chosen in the minimization procedure subject to the constraint that this share matches the value observed in the data. Based on U.S. consumption expenditure data reported in Lebergott (1996), on average, this share was 0.89 over the period 1910-1970. This requires $\alpha=8.09 \zeta$. The parameters determining the benefits of leisure travel, $\eta$ and $\theta$, are determined by the minimization procedure.

3.1.4. Abilities. In the model, $w \lambda$ is the maximum amount of earnings that a household with earning ability $\lambda$ can obtain by spending all its time endowment on work over a five-year period. The cross-sectional variations in $w \lambda$ are driven by the variations in $\lambda$ across households. For each decennial year $t$ between 1910 and 1970, the logarithm of $\lambda_{t}$ is assumed to be normally distributed with mean $\mu_{t}$ and variance $\sigma_{t}^{2}$.

Since there is no real-world counterpart for $w_{t} \lambda_{t}$, its distribution is constructed using various sources of data, including (i) average hourly earnings and employment across major industries over the period 1936-1970, (ii) time use data, and (iii) labor-force participation rate among married women. Details of this procedure can be found in the data appendix. Once the mean and variance of $w_{t} \lambda_{t}$ are known, they can be used to determine the values of $\mu_{t}, \sigma_{t}$, and $w_{t}$ under the lognormal distribution assumption and a normalization of the mean ability levels. After $\mu_{t}$ and $\sigma_{t}^{2}$ are determined, the lognormal distribution is truncated so as to encompass $99 \%$ of the underlying population, omitting $0.5 \%$ from each side. The values of $\mu_{t}, \sigma_{t}$, and $w_{t}$ at each date $t$ are given in Table 4. Notice that wages increase over the period, generating a rise in real income in the model.

3.1.5. Agricultural rent. The rental rate of agricultural land, $q_{A, t}$, is set to the rent paid for an average single-family-sized lot of farmland at each date. ${ }^{26}$ The rental rate in each steady state is given in Table 4.

3.1.6. Car prices and transportation costs. Car prices between 1910 and 1970 are calibrated using data on quality-adjusted prices reported in Raff and Trajtenberg (1997) (see footnote 11 for details) and reported in Table $4 .{ }^{27}$ Car price for the steady state in 1910 is the average

25 For bus users, transportation expenses refer to the fixed costs of using the bus. For car owners, these expenses include the price of a car and the fixed costs of operating the car.

26 The rental rate for an average single-family-sized lot of farmland is the gross rent paid for an acre of farmland divided by the number of average-sized lots in an acre. Data on gross rent are obtained from the U.S. Department of Agriculture Economic Research Service, the Census of Agriculture, the Farm Costs and Returns Survey, and the Farm Finance Survey. The number of average-sized lots in an acre is the average lot size for a single-family home taken from the National Association of Realtors.

27 The quality-adjusted prices reported in this study are for new cars only. Since the model is static, the price of "owning a car" is essentially the price of access to a car for one model period, or five years. Since the average duration 
quality-adjusted price over the period 1906-1910. The same rule applies to the other steady states. Notice that car prices consistently fall over the 1910-1970 period.

In each steady state, there are four parameters governing the transportation costs, namely, $\gamma_{b, t}, \gamma_{c, t}, \psi_{b, t}$, and $\psi_{c, t}$. The parameters $\gamma_{b, t}$ and $\gamma_{c, t}$ capture the fixed costs of using the bus and operating a car, respectively. The time costs of using the two modes of transportation are determined by $\psi_{b, t}$ and $\psi_{c, t}$. Unfortunately, data on these costs for the time period in question are very scarce. Hence, a number of these parameters have to be determined by the minimization procedure.

3.1.7. Automobile. In the model, the parameter $\psi_{c}$ is the time required to travel one unit distance by car. One possible way of calibrating this is to exploit travel time data for car users. These kinds, of data, however, are very scarce for the period in question. The only data source available is the National Personal Transportation Survey conducted in 1969. According to this study, the average time to commute one mile by car was 3.63 minutes in $1970 .{ }^{28}$ When translated to model units, this means $\psi_{c, 1970}=0.0054 .^{29}$

For the other decennial years, the time cost of traveling by car is assumed to be a function of the availability and quality of roads, measured by the total mileage of paved urban roads per 1,000 urban population. Figure 5 plots the time series of this measure over the period 1906$1970 .^{30}$ Throughout this time period, the total mileage of paved urban roads per 1,000 urban population rose at an average annual rate of about 3.5\%. For each decennial year $t$ from 1910 to 1960 let $R_{t}$ denote the average total mileage over the $t-4$ to $t$ period. The time cost is then assumed to be the decreasing function of $R_{t}$,

$$
\psi_{c, t}=\Phi R_{t}^{-\kappa}
$$

The parameters $\Phi$ and $\kappa$ are chosen through the minimization procedure subject to the constraint that $\psi_{c, 1970}=0.0054$.

The fixed costs of traveling by car are calibrated using data on car-related consumption expenditures reported in Lebergott (1996). The data include expenditures on tires and accessories, gasoline, oil, repairs, automobile insurance, and tolls. The fixed costs parameter $\gamma_{c, t}$ is equated to the five-year total expenditures per registered vehicle. ${ }^{31}$ The costs are given in Table 8, below. The daily fixed costs decrease from approximately 14 (constant 2000) dollars in 1910 to 5.42 dollars in 1970.

3.1.8. Bus. The efficiency of many forms of public transportation such as streetcars and motor buses also depends on the quantity and quality of roads per person. Thus, the time cost of commuting by bus is assumed to be a function of both the quantity of paved urban roads per urban person and the value of equipment and structures in public transit per urban person. Figure 6 shows the value of the stock of equipment and structures per urban person for intercity

of a passenger car in the United States during 1950-1970 is about five years, the price of a new car is a reasonable proxy for this price. The underlying assumption is that the price for a new car that lasts five years is more or less the same as the costs of purchasing multiple used cars within five years. This is one reason why a used car market is not explicitly introduced in the current model. Insufficient information about the used car market is another reason. In order to add a nontrivial used car market, data on used car prices and the share of households who own used cars would be necessary for the quantitative analysis. These data, however, are not available for the period in question.

28 Source: Authors' calculations based on the data reported in Table A20 in National Personal Transportation Survey: Home-to-Work Trips and Travel Report No. 8, August 1973.

29 Consider a car owner who has to take a round-trip between home and work each day for five days a week. The total time spent on commuting is $3.63 \times 2 \times 5=36.3$ minutes per week. Assume that the agent is awake for 16 hours a day. The total amount of time available is $16 \times 60 \times 7=6720$ minutes per week. The parameter $\psi_{c, t}$ at $t=1970$ is given by $36.3 / 6720=0.0054$.

30 Details on this data are given in the Appendix.

31 Since there are no costs of traveling by car that depend on distance and are independent of ability, the fixed cost is an average of all the costs of traveling by car except the time cost. 


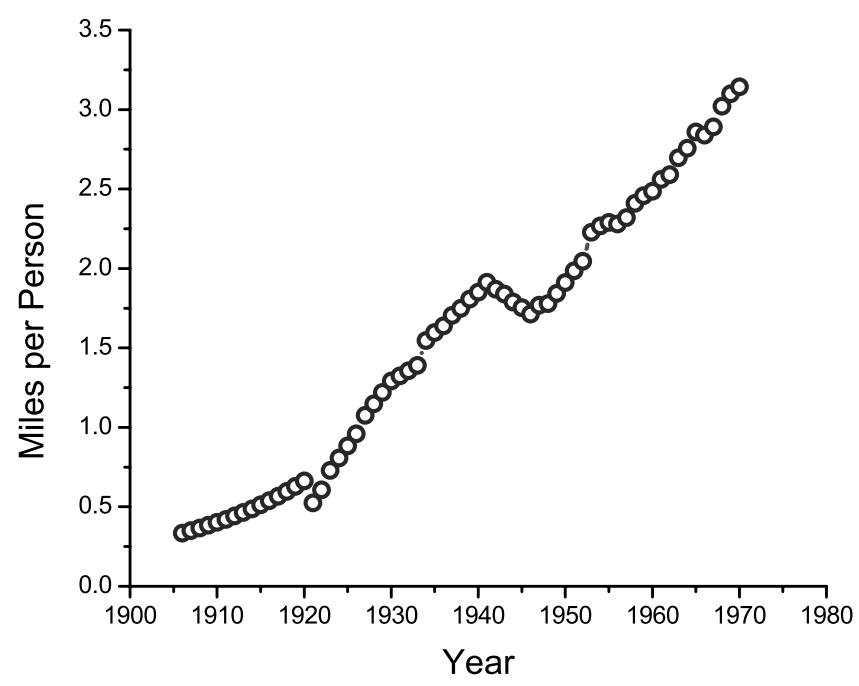

SOURCE: See footnote 30.

Figure 5

MILES OF PAVED URBAN ROAD PER URBAN POPULATION: 1906-1970

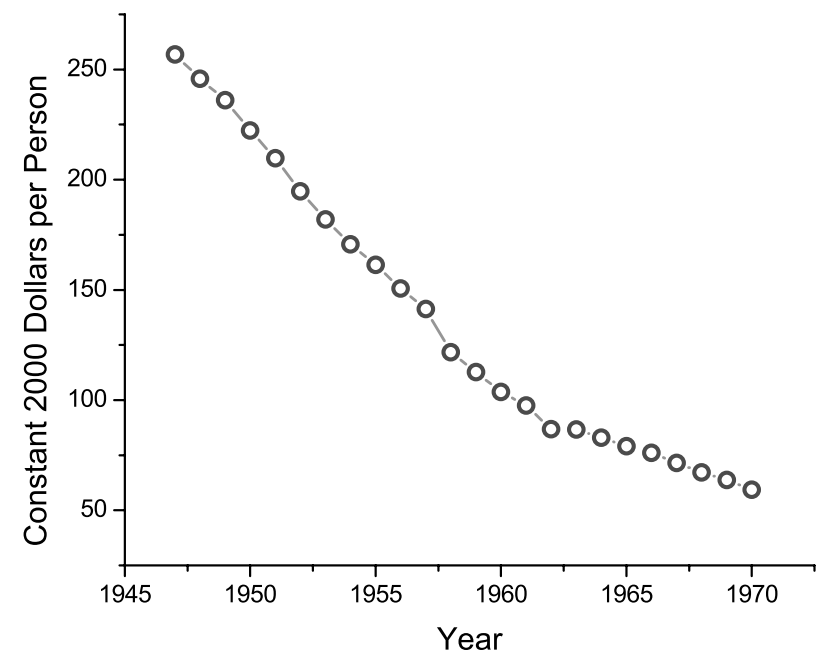

SourcE: Fixed Reproducible Tangible Wealth in the United States, 1925-1970.

Figure 6

CAPITAL STOCK OF EQUIPMENT AND STRUCTURES FOR INTERCITY AND LOCAL PASSENGER TRANSIT PER URBAN POPULATION, 1947-1970

and local passenger transit over the period 1947-1970. The value is a measure of both the quantity and the quality of the pubic transit stock. The value declined steadily over this time period at an annual rate of $6 \%$. Evidence shows that the decline in public transit began much earlier than 1947. First, public transit ridership per capita has been persistently declining since the 1920s as shown in Figure 7. Second, net capital expenditures on transit equipment and structures were negative for the period 1920-1950 (Table 5). This suggests that the public transit sector has been disinvesting since the 1920s. Given this evidence, it seems reasonable to assume that the capital stock in public transit has been declining since, at least, 1930. On the one hand, this decline suggests of decrease in services, which should raise the time costs of using public transit by lengthening waiting times and increasing the distances between stops. However, on the other 


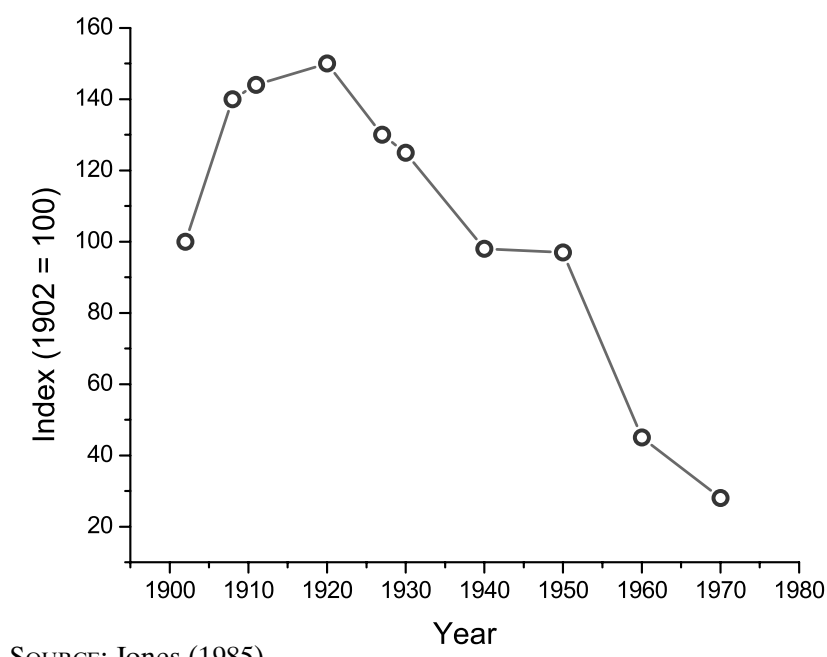

FIGURE 7

PUBLIC TRANSIT RIDERSHIP PER CAPITA, 1902-1970

TABLE 5

NET CAPITAL EXPENDITURES OF URBAN TRANSIT PROPERTIES, 1890-1950

\begin{tabular}{lccccccr}
\hline Year & 1890 & 1900 & 1910 & 1920 & 1930 & 1940 & 1950 \\
\hline Net expenditures $^{\mathrm{a}}$ & 74.0 & 170.9 & 66.1 & -128.5 & -82.3 & -10.4 & -53.5 \\
\hline
\end{tabular}

${ }^{a}$ Millions of 1929 dollars.

Source: Ulmer (1960).

hand, the increasing quantity and quality of roads should make certain forms of public transit such as buses more efficient, reducing time costs. Which of these two effects dominates will come out of the minimization procedure.

The ideas mentioned above are captured formally as follows. Let $P_{t}$ denote the $t-4$ to $t$ five-year average of the stock of equipment and structures in public transit per urban person. For the decennial years between 1930 and 1970, the time cost parameter for bus is assumed to be

$$
\psi_{b, t}=\Gamma R_{t}^{\rho-1} P_{t}^{-\rho}
$$

where $R_{t}$ is the total mileage of paved urban roads per 1,000 urban population as defined above. The parameters $\Gamma$ and $\rho$ are chosen through the minimization procedure. For the years 1926$1947 P_{t}$ is estimated using a linear trend. The trend is not extended to the years before 1926 because it is questionable whether the capital stock was declining during these early years. Instead it is assumed that $\psi_{b, t}$ is growing at a constant rate prior 1930 so that

$$
\psi_{b, t}=\Psi(g)^{\frac{t-1910}{1910}}, \quad \text { for } 1910 \leq t \leq 1930 .
$$

The parameters $\Psi$ and $g$ are again determined by the minimization procedure subject to the constraint that $\psi_{b, 1930}$ is the same whether obtained by (23) or (24).

The fixed costs of traveling by bus are calibrated using U.S. consumption expenditure data on local public transit over the period 1900-1970 taken from Lebergott (1996). The values of $\gamma_{b, t}$ are obtained by dividing the total expenditures on local public transit over $t-4$ to $t$ by the number of households without cars. The costs are given in Table 7, below. The daily fixed costs, 
for the most part, increase over the 1910-1970 period from 1.81 (constant 2000) dollars in 1910 to 4.26 dollars in 1970 .

3.2. Minimization Procedure. Ten parameters are still undetermined up to this point. These include the preference parameters, $\alpha$ and $\zeta$, the parameters governing the benefits of leisure travel, $\eta$ and $\theta$, the time cost parameters for automobile, $\Phi$ and $\kappa$, and the time cost parameters for bus, $\Gamma, \rho, \Psi$, and $g$. Let $\boldsymbol{\theta}$ denote the vector of unknown parameters. In the minimization procedure, the vector $\theta$ is chosen so as to minimize the discrepancies between the model's predictions and the observed data. The choice of $\boldsymbol{\theta}$ is subject to three constraints. First, the preference parameters $\alpha$ and $\zeta$ are chosen so that the share of expenditures on consumption goods matches the data. This requires

$$
\alpha=8.09 \zeta
$$

Second, the time cost parameters for automobile ( $\Phi$ and $\kappa)$ are chosen so that the predicted value of $\psi_{c, 1970}$ is consistent with the average time spent on traveling one mile by car observed in the data. This requires

$$
\psi_{c, 1970}=\Phi R_{1970}^{-\kappa}=0.0054
$$

Third, the time cost parameters for bus are chosen so that the value of $\psi_{b, 1930}$ as predicted by (23) is consistent with that predicted by (24). This means

$$
\Gamma R_{1930}^{\rho-1} P_{1930}^{-\rho}=\Psi(g)^{\frac{1930-1910}{1910}} .
$$

After taking into account these constraints, seven degrees of freedom remain. These are chosen to match 10 targets: (i) the mean population density gradients for each decennial year between 1910 and 1940, (ii) the percentage of car owners in each decennial year between 1910 and 1970 (excluding 1930 and 1940, when data is unavailable), and (iii) the fraction of total miles driven by car users for commuting in 1970. At each date $t$, denote the model's prediction on the percentage of car ownership by $V_{t}(\theta)$, the population density gradient by $D_{t}(\theta)$, and the fraction of total miles driven by car users for commuting by $M_{t}(\theta)$. In order to compute the population density gradient, the population density at 1,000 locations in $\left[0, \widetilde{x}_{t}\right]$ is computed. Let $\left\{x_{i, t}\right\}$ and $\left\{y_{i, t}\right\}$ be the set of locations and the sample population densities, respectively. The population density gradient $D_{t}(\boldsymbol{\theta})$ is obtained from the following regression:

$$
\ln y_{i, t}=A_{t}+D_{t}(\theta) \ln x_{i, t}+\varepsilon_{t} .
$$

In all the experiments later, the $R^{2}$ of (28) is always greater than 0.8 . The fraction of total miles driven by car users for commuting is given by

$$
M_{t}(\boldsymbol{\theta})=\frac{\int x_{c, t}(\lambda ; \boldsymbol{\theta}) \Omega_{t}(\lambda ; \boldsymbol{\theta}) d F(\lambda)}{\int\left[x_{c, t}(\lambda ; \boldsymbol{\theta})+z_{c, t}(\lambda ; \boldsymbol{\theta})\right] \Omega_{t}(\lambda ; \boldsymbol{\theta}) d F(\lambda)},
$$

where $\Omega_{t}(\lambda ; \theta)$ is the indicator function defined in (15).

In the minimization procedure, $\theta$ is chosen so as to minimize the sum of the deviations between the model's output and the observed data, subject to the three constraints described earlier. Formally, let $v_{t}$ denote the actual percentage of car ownership in the United States at time $t, d_{t}$ be the actual population density gradient for an average American city, and $m_{1970}$ 
TABLE 6

PARAMETER VALUES DETERMINED IN MINIMIZATION PROCEDURE

\begin{tabular}{|c|c|c|c|c|c|c|c|c|c|}
\hline \multicolumn{4}{|c|}{ Preferences } & \multicolumn{4}{|c|}{ Bus Time Cost } & \multicolumn{2}{|c|}{ Car Time Cost } \\
\hline$\alpha$ & $\zeta$ & $\eta$ & $\theta$ & $\Gamma$ & $\rho$ & $\Psi$ & $g$ & $\Phi$ & $\kappa$ \\
\hline 0.79 & 0.10 & 0.56 & 0.17 & 0.13 & $5.6 \times 10^{-4}$ & $6.0 \times 10^{-2}$ & 1.40 & $5.4 \times 10^{-3}$ & $1.3 \times 10^{-3}$ \\
\hline
\end{tabular}

TABLE 7

TRAVEL AND COMMUTING COSTS FOR BUS USERS UNDER THE BASELINE CALIBRATION

\begin{tabular}{lcrrrrrrr}
\hline & Parameter & 1910 & 1920 & 1930 & 1940 & 1950 & 1960 & 1970 \\
\hline $\begin{array}{l}\text { Travel costs } \\
\quad \text { Fixed cost (\$/day) }\end{array}$ & $\gamma_{b, t}$ & 1.81 & 2.41 & 1.35 & 1.46 & 2.64 & 3.47 & 4.26 \\
$\quad \begin{array}{l}\text { Time cost (min/mile) } \\
\begin{array}{l}\text { Commuting costs } \\
\text { Average variable cost (\$/day) }\end{array}\end{array}$ & $\tau_{b, t}$ & 40.32 & 56.34 & 78.73 & 51.27 & 49.77 & 37.56 & 29.97 \\
\hline
\end{tabular}

be the fraction of total miles driven by car users for commuting in 1970 . Then $\boldsymbol{\theta}$ is chosen by solving

$$
\min _{\boldsymbol{\theta}}\left\{\sum_{t=1910}^{1920}\left[v_{t}-V_{t}(\boldsymbol{\theta})\right]^{2}+\sum_{t=1950}^{1970}\left[v_{t}-V_{t}(\boldsymbol{\theta})\right]^{2}+\sum_{t=1910}^{1940}\left[d_{t}-D_{t}(\boldsymbol{\theta})\right]^{2}+\left[m_{1970}-M_{1970}(\boldsymbol{\theta})\right]^{2}\right\},
$$

subject to (25)-(27). The parameter values determined by the minimization procedure are presented in Table 6.

\section{THE BASELINE ECONOMY}

4.1. Analysis. In this section, the results of the minimization procedure are discussed. First, a discussion of the costs of commuting by bus and car under the baseline calibration is provided. Then the earnings distribution in the baseline model is discussed. Finally, the ability of the model to successfully match the targeted rise in car ownership in the United States and the prewar suburbanization trend is explored, followed by a discussion of the model's ability to account for the postwar suburbanization trend in the United States.

To begin with, consider the transportation costs. Table 7 contains the fixed and time costs of commuting by bus under the baseline calibration. All costs are presented in constant 2000 dollars. The table also provides a measure of average variable cost of commuting by bus. Formally, this is the amount of wage income forgone due to commuting for an average bus user (one who lives at the average distance from the CBD). Similarly, Table 8 presents the fixed and time costs of traveling for a car owner as well as the average variable cost of commuting by car.

First, consider the costs associated with taking public transit. The fixed cost of riding the bus was calibrated directly to match the data. As explained in Section 3, the time cost of commuting by bus is determined in two steps. From 1930 on, the time cost parameter is a function of the amount of paved urban roads and public transit capital stock per urban person. For years prior to 1930, the parameter is assumed to grow (or shrink) at a constant rate. Surprisingly, the minimization procedure finds that the time cost of commuting by bus in later years depends primarily on the amount of paved urban road as opposed to the stock of public transit equipment and structures. In addition, the minimization sets the growth rate in the cost of commuting by bus in the early years to a positive value. Thus, as can be seen in Table 7, the time cost of using the bus under the baseline calibration increases in early years and decreases in later years as the amount of paved urban roads rises. The average variable cost decreases quickly from 1910 to 
TABLE 8

TRAVEL AND COMMUTING COSTS FOR CAR OWNERS UNDER THE BASELINE CALIBRATION

\begin{tabular}{lcccccccc}
\hline & Parameter & 1910 & 1920 & 1930 & 1940 & 1950 & 1960 & 1970 \\
\hline Travel costs & & & & & & & & \\
$\quad$ Fixed cost (\$/day) & $\gamma_{c, t}$ & 13.98 & 6.15 & 3.92 & 3.98 & 4.43 & 5.25 & 5.42 \\
$\quad \begin{array}{l}\text { Time cost (mins/mile) } \\
\text { Commuting costs }\end{array}$ & $\tau_{c, t}$ & 3.638 & 3.636 & 3.634 & 3.631 & 3.631 & 3.630 & 3.629 \\
$\quad$ Average variable cost (\$/day) & & - & 10.22 & 7.29 & 7.89 & 8.81 & 10.92 & 11.39 \\
\hline
\end{tabular}

TABLE 9

TRAVELING STATISTICS UNDER BASELINE CALIBRATION

\begin{tabular}{|c|c|c|c|c|c|c|c|}
\hline & 1910 & 1920 & 1930 & 1940 & 1950 & 1960 & 1970 \\
\hline \multicolumn{8}{|c|}{ Average percentage of time spent commuting } \\
\hline Bus users & 5.9 & 6.6 & 6.1 & 4.8 & 3.1 & 2.3 & 1.5 \\
\hline Car owners & - & 1.6 & 1.4 & 1.5 & 1.3 & 1.3 & 1.2 \\
\hline \multicolumn{8}{|c|}{ Average percentage of time spent on noncommuting travel } \\
\hline Bus users & 2.0 & 1.9 & 2.0 & 2.0 & 2.0 & 2.1 & 2.1 \\
\hline Car owners & - & 1.6 & 1.8 & 1.9 & 1.9 & 2.0 & 2.0 \\
\hline \multicolumn{8}{|c|}{ Commuting's percentage of total miles traveled } \\
\hline Bus users & 75.1 & 77.5 & 75.4 & 70.3 & 60.5 & 53.2 & 34.6 \\
\hline Car owners & - & 50.1 & 45.0 & 45.2 & 40.5 & 39.9 & 37.4 \\
\hline
\end{tabular}

1930 and then rises slightly. This cost is determined by (i) the location of the average bus user, (ii) his ability level, (iii) the real wage for an effective unit of labor, and (iv) the time cost of commuting by bus. The rising time cost in early years encourages wealthy bus users to switch to cars and poorer bus users to move closer to the city center, reducing the average variable cost of commuting conditional on being a bus user. In later years, the rise in the average variable cost of commuting by bus is driven by the increases in real wages.

Now consider the transportation costs associated with being a car owner. The fixed cost of commuting by car was already calibrated to match the data. In addition, the time cost of commuting one mile by car in 1970 is set to match the average number of minutes to commute a mile by car from the data. The time cost in earlier years is assumed to be a function of the miles of paved urban roads per urban person. The model finds, as expected, that the time spent commuting is inversely related to the miles of urban roads. However, the time cost only slightly decreases over the 1910-1970 period. Since the model predicts zero car owners in 1910, it is not possible to compute the variable cost for this year. The average variable cost falls between 1920 and 1930 then rises from 1930 to 1970. The average variable cost is determined by (i) the location of the average car owner, (ii) his ability level, (iii) the real wage for an effective unit of labor, and (iv) the time cost of commuting by car. In the earlier years, the income level of the car owner at the average distance decreases as relatively lower income bus users switch to cars, reducing the average variable cost of car owners. However, in later years, the overall rising real wages plays a dominant role, increasing the value of the average car owner's time and hence his variable cost.

Table 9 gives the percentage of time spent commuting for the bus user and car owner at the average distance from the CBD in each period. It also shows the average percentage of time spent on leisure travel and commuting's share of total miles traveled for both groups in each period. Note that the minimization procedure was able to successfully target commuting's percentage of total miles traveled in 1970. Time spent commuting by both public transit and automobile decreases over time, whereas time spent on leisure travel slightly increases. Two things can be observed when comparing between bus users and car owners in the model. First, in all periods bus users spend more time commuting to work than car owners. Second, car owners spend a larger fraction of their total travel time and travel miles on leisure trips than bus users. The first prediction is qualitatively consistent with the data. According to the 1980 Census, the mean 
TABLE 10

EARNINGS DISTRIBUTION GENERATED UNDER THE BASELINE CALIBRATION

\begin{tabular}{lccccccc}
\hline & 1910 & 1920 & 1930 & 1940 & 1950 & 1960 & 1970 \\
\hline $\begin{array}{l}\text { Mean }\left(\$ \text { year }^{\mathrm{a}}\right) \\
\text { Datab }\end{array}$ & 11,472 & 12,029 & 15,190 & 18,076 & 24,737 & 33,626 & 41,741 \\
$\begin{array}{l}\text { Model } \\
\begin{array}{l}\text { SD/mean } \\
\text { Model }\end{array}\end{array}$ & 11,812 & 13,051 & 14,801 & 18,775 & 25,344 & 32,584 & 40,802 \\
\hline
\end{tabular}

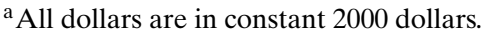

bSource: See "Household Earnings" in the data section of the Appendix.

TABLE 11

BASELINE MODEL RESULTS

\begin{tabular}{|c|c|c|c|c|c|c|c|}
\hline & 1910 & 1920 & 1930 & 1940 & 1950 & 1960 & 1970 \\
\hline \multicolumn{8}{|c|}{ Car ownership (\%) } \\
\hline Data & 2.3 & 33 & \multicolumn{2}{|c|}{$44^{\mathrm{a}}$} & 59 & 77 & 82 \\
\hline Model & 0 & 10 & 43 & 43 & 69 & 71 & 86 \\
\hline \multicolumn{8}{|c|}{ Population density gradient } \\
\hline \multirow{3}{*}{$\begin{array}{l}\text { Data } \\
\text { Model }\end{array}$} & 0.83 & 0.79 & 0.66 & 0.61 & 0.39 & 0.31 & 0.23 \\
\hline & 0.86 & 0.83 & 0.62 & 0.56 & 0.46 & 0.46 & 0.38 \\
\hline & $(0.965)^{\mathrm{b}}$ & $(0.993)$ & $(0.996)$ & $(0.995)$ & $(0.974)$ & $(0.968)$ & $(0.916)$ \\
\hline \multicolumn{8}{|c|}{$\%$ Change in gradient } \\
\hline Data & & -4.8 & -16.5 & -7.6 & -36.1 & -20.5 & -25.8 \\
\hline Model & & -3.0 & -25.6 & -9.5 & -18.2 & 0.0 & -17.4 \\
\hline
\end{tabular}

a This figure is for the period 1934 to 1936.

${ }^{\mathrm{b}}$ The numbers in parenthesis are the R-squares of the regression in (28).

travel time to work for public transportation users and car users were 42.3 and 21.0 minutes, respectively. Very little data about travel patterns is available for the period in question. Thus, the actual fraction of time spent on commuting and leisure travel is unknown.

Now the average annual earnings of households in the model is compared to the average annual earnings of urban and nonfarm households in the data. The earnings distribution in the model economy is endogenous since agents choose their time spent working. Table 10 contains the means and normalized standard deviations of each periods' earnings distribution. Average annual earnings increase from approximately 12,000 dollars in 1910 to 41,000 dollars in 1970. The table also contains the average annual earnings of urban households for the decennial years between 1910 and $1970 .{ }^{32}$ Average annual earnings in the model line up well with the data. Thus, the model accurately generates the growth rate in real earnings for urban households that is observed in the data.

The model is able to generate the rise in car ownership over the 1910-1970 period and the suburbanization trend in the prewar period. The car-ownership rates and population density gradients under the baseline calibration and in the data are provided in Table 11. The model has difficulty in matching the level of car owners observed in the data in 1910 and 1920. In 1910, the high price and fixed cost of cars deter even the wealthiest agents in the model from purchasing them, and even though car prices decline substantially, only $10 \%$ of the population purchases a car in 1920 compared to $33 \%$ in the data. However, the model is able to match the level of car ownership in later years. The large increase in car ownership between 1940 and 1950 is mostly driven by the large rise in real wages during this decade. The model does a good job tracking the population density gradient observed in the data over the 1910-1940 period. If anything, it slightly overestimates the degree of suburbanization during this period.

The model is able to account for $60 \%$ of the rise in suburbanization during the postwar period. This can be seen by comparing the population density gradients predicted by the model for the

32 Details on the household earnings data can be found in the data section of the Appendix. 
TABLE 12

COUNTERFACTUAL EXPERIMENTS

\begin{tabular}{|c|c|c|c|c|c|c|c|c|}
\hline & & 1910 & 1920 & 1930 & 1940 & 1950 & 1960 & 1970 \\
\hline & \multicolumn{8}{|l|}{ Data } \\
\hline & Car owners & 2.3 & 33 & \multicolumn{2}{|c|}{$44^{\mathrm{a}}$} & 59 & 77 & 82 \\
\hline & Density gradient & 0.83 & 0.79 & 0.66 & 0.61 & 0.39 & 0.31 & 0.23 \\
\hline & \multicolumn{8}{|l|}{ Baseline model } \\
\hline & Car owners & 0 & 10 & 43 & 43 & 69 & 71 & 86 \\
\hline & Density gradient & 0.86 & 0.83 & 0.62 & 0.56 & 0.46 & 0.46 & 0.38 \\
\hline \multirow[t]{3}{*}{1.} & \multicolumn{8}{|c|}{ No population growth } \\
\hline & Car owners & 0 & 9 & 42 & 42 & 67 & 69 & 85 \\
\hline & Density gradient & 0.86 & 0.86 & 0.63 & 0.56 & 0.44 & 0.44 & 0.33 \\
\hline \multirow[t]{3}{*}{2.} & \multicolumn{8}{|c|}{ Price of car remains at 1910 value } \\
\hline & Car owners & 0 & 0 & 5 & 6 & 14 & 18 & 22 \\
\hline & Density gradient & 0.86 & 1.19 & 1.07 & 0.85 & 0.71 & 0.64 & 0.55 \\
\hline \multirow[t]{3}{*}{3.} & \multicolumn{8}{|c|}{ Wage distribution remains as in 1910} \\
\hline & Car owners & 0 & 7 & 31 & 19 & 25 & 15 & 17 \\
\hline & Density gradient & 0.86 & 0.92 & 0.69 & 0.69 & 0.66 & 0.68 & 0.63 \\
\hline \multirow[t]{3}{*}{4.} & \multicolumn{8}{|c|}{ Time and fixed cost of car travel remains as in 1910} \\
\hline & Car on & 0 & 0 & 7 & 7 & 20 & 26 & 36 \\
\hline & Density gradient & 0.86 & 1.17 & 1.01 & 0.83 & 0.66 & 0.59 & 0.50 \\
\hline \multirow[t]{3}{*}{5.} & \multicolumn{8}{|c|}{ Time and fixed cost of public transit remains as in 1910} \\
\hline & Car ow & 0 & 4 & 23 & 36 & 56 & 63 & 80 \\
\hline & Density gradient & 0.86 & 0.83 & 0.62 & 0.56 & 0.48 & 0.48 & 0.41 \\
\hline
\end{tabular}

a $1934-36$

postwar period to those in the data. The postwar suburbanization trend in the model is more gradual than that observed in the data: The population density gradient decreases from 0.56 in 1940 to 0.38 in 1970 compared to a decrease from 0.61 in 1940 to 0.23 in 1970 in the data. Thus, the driving forces of suburbanization in the model are able to account for approximately $60 \%$ of the 38 point decrease in the population density gradient from 1940 to 1970.

4.2. Counterfactual Experiments. Table 12 provides the results of a series of counterfactual experiments. Each experiment consists in shutting down one of the factors that impact suburbanization and car ownership: population growth, falling prices of cars, rising real wages, changing time and fixed costs of traveling by car, and changing costs of traveling via public transportation. Here "shutting down" means keeping it fixed at its 1910 level. The counterfactual experiments can be used to assess the role that various factors play in generating the increasing trend in car ownership and decreasing density gradient.

According to the model, the growth in urban population over the 1910-1970 period had only a small impact on both car-ownership rates and suburbanization. This can be seen by comparing the baseline car-ownership rates and density gradients to those obtained when the urban population size remains fixed at its level in 1910 (experiment 1). Intuitively, an increase in population size has two opposing effects on suburbanization, thus making the overall effect relatively small. Holding all else constant, an increase in the size of the urban population raises the demand for land in every location and hence bids up rents. This creates an incentive for agents to move further away from the city center in order to economize on rent. As a result, the extent of suburbanization increases. However, the increase in rent also lowers individuals' demand for land, more so for the wealthy than the poor, and reduces the benefits of living far from the city center. This results in less suburbanization. Notice that in the earlier periods the first effect dominates: In the baseline model with urban population growth there is more suburbanization than in the version without population growth. However, as agents become wealthier and move further from the city center, acquiring more land, population growth has the opposite effect 
on suburbanization, that is, the second effect starts to dominate. This is because the marginal utility from an additional unit of land is lower for the wealthier agents in later years when land consumption is already relatively high.

Also, according to the model, declining automobile prices, followed by decreases in the time and fixed cost of commuting by car, were the dominant drivers of suburbanization over the period 1910-1950, whereas, from 1950 to 1970, suburbanization was due primarily to rising real incomes. These results can be seen by comparing experiments $2-5$. In experiment 2 , the price of automobiles in each period is set to its level in 1910, thus shutting down the decrease in car prices under the baseline calibration. In experiment 3, the mean and standard deviation of wages in each period are set to their values in 1910: thus there is no growth in real wages or changes in the wage distribution across the steady states. In experiment 4 , both the time and fixed cost of traveling by car in each period are set to their values in 1910, thus shutting down the decrease in the costs of traveling by car under the baseline calibration. Finally, in experiment 5 , both the time and fixed costs of traveling via public transportation in each period are set to the levels in 1910, shutting down the changes in the cost of traveling by bus that occur in the baseline model.

Notice that in all scenarios except scenario 5, the city initially increases in density, that is, centralization as opposed to suburbanization, occurs. This happens for the following reasons. First, the time costs of traveling by public transit are increasing during the early years. This induces the bus users to live closer to the city center. Second, cars are now more expensive to own or to use due to a constant car price, constant costs of traveling by car, or a constant real income. As a result, more agents choose to use the bus and stay close to the city center. From 1910 to 1920, the most centralization occurs under experiment 2, when car prices do not decline, followed by experiment 4 where the costs of traveling by car are fixed. Subsequently, from 1920 to 1950 the degree of suburbanization is lowest in experiment 2, again followed by experiment 4. Thus, decreases in automobile prices are the dominant driver of suburbanization over the 1910-1950 period. The removal of the declining time and fixed costs of traveling by car has the second largest positive impact on the population density gradients over this period.

From 1950 to 1970 real wages grow at an accelerated rate and become the dominant driver of suburbanization. This can be seen by noting that the density gradient is relatively the highest under experiment 3 in both 1960 and 1970. Falling automobile prices are the second most important driver of suburbanization over this period.

The changes in the time and fixed costs of traveling using public transportation have a relatively small impact on both suburbanization and car ownership. This can be seen by comparing experiment 5 to the baseline case. Keeping these costs fixed at their 1910 levels delays the switch to cars initially. This is because the costs of traveling by bus do not increase, which makes cars relatively fewer attractive. However, as agents become wealthier and cars more affordable, fewer agents remain to be bus users, and the rates of car ownership are closer to those in the baseline case.

\section{CONCLUSION}

A heterogeneous-agent model of car ownership and location choice is constructed. An agent, in the model, can choose his residential location and decide whether or not to own a car. Under the given specification, it is shown that wealthy agents (those with high abilities) tend to own a car and live further away from the city center, whereas poor agents tend to travel by bus and stay close to the city center. The model is then calibrated using U.S. data. It is able to generate the increase in car ownership observed in the data over the period 1910-1970 and the suburbanization trend in the prewar period. The model predicts that rising real wages, falling prices of automobiles, and changes in the costs of traveling by both cars and public transportation can account for $60 \%$ of postwar suburbanization. According to the model, decreasing automobile prices were the dominant driver of suburbanization from 1910 to 1950 followed by reductions in the time and fixed costs of traveling by car. However, from 1950 to 1970 rising real wages played the 
dominant role followed by decreasing car prices. The rise in urban population and changes in the costs of traveling via public transportation had only a small effect on suburbanization.

This study is a first attempt at calibrating and computing a spatial model with heterogeneous agents. In order to keep the analysis manageable, several simplifying assumptions are made. First, this study abstracts from the decentralization of firms and employment. However, empirical evidence suggests that transportation innovations have impacted their spatial distribution as well. Early studies such as Moses and Williamson (1967) and Ward (1971) describe how intra-city trucking reduced the costs of freight transport during the first half of the 20th century and encouraged the decentralization of manufacturing employment. White (1976) presents a theoretical model of firm location in which a decline in freight transport costs induces firms to sprawl. By enhancing the mobility of workers, the diffusion of the automobile has also encouraged suburbanization of manufacturers and retailers. One direction of future research would be to assess the impact of the automobile on the decentralization of employment.

Second, this study assumes that the supply of housing units is exogenously given. The model developed in here can be readily extended to incorporate a group of profit-maximizing developers who determine the amount of housing in the city. This extension, however, would not be trivial. Endogenizing housing supply would introduce another function, which specifies the quantity of housing units in each location in the city, into the equilibrium of the model. This would in turn increase the dimension of the differential equation system and the complexity of the numerical analysis.

\section{APPENDIX}

\section{A.1. Proofs}

Proof of Lemma 1. First we derive the explicit form of $W^{b}(\lambda, x)$. Taking logarithm on both sides of (10) and rearranging terms gives

$$
\ln z_{b}(\lambda, x)=\ln (1-\widetilde{\alpha}-\tilde{\zeta})+\ln \left\{w \lambda\left[1-\tau_{b}(x)\right]-\gamma_{b}\right\}-\ln w \lambda-\ln \psi_{b}
$$

Substituting (8), (9), and the above expression into the utility function gives

$$
\begin{aligned}
W^{b}(\lambda, x)= & \xi+\tilde{\theta} \ln \left\{w \lambda\left[1-\tau_{b}(x)\right]-\gamma_{b}\right\}-\zeta \ln q(x)-(1-\alpha-\zeta) \theta\left(\ln \psi_{b}+\ln w \lambda\right) \\
& -(1-\alpha-\zeta) \eta x
\end{aligned}
$$

where $\xi$ is some constant and $\widetilde{\theta} \equiv \alpha+\zeta+(1-\alpha-\zeta) \theta>0$.

Next we turn to the constraint set. Since it is never optimal to have $w \lambda\left[1-\tau_{b}(x)\right]=\gamma_{b}$, the optimal location $x_{b}(\lambda)$ must be contained in the following set,

$$
\widetilde{\mathcal{D}}(\lambda) \equiv\left\{x \geq 0: w \lambda\left[1-\tau_{b}(x)\right]>\gamma_{b}\right\}
$$

for any $\lambda$ in $\left[\lambda_{\min }, \lambda_{\max }\right]$. Similar to $\mathcal{D}(\lambda)$ defined in the text, $\widetilde{\mathcal{D}}(\lambda)$ is also an interval on the positive real line. In particular, $x=0$ is the smallest element of $\widetilde{\mathcal{D}}(\lambda)$ for any $\lambda$ in $\left[\lambda_{\min }, \lambda_{\max }\right]$. Since $w \lambda\left[1-\tau_{b}(x)\right]$ is increasing in $\lambda$, it follows that $\lambda_{2}>\lambda_{1}$ implies $\widetilde{\mathcal{D}}\left(\lambda_{1}\right) \subseteq \widetilde{\mathcal{D}}\left(\lambda_{2}\right)$ Intuitively, this means rich agents can afford to live further away from the CBD.

Pick any $\lambda_{2}>\lambda_{1}$ in $\left[\lambda_{\min }, \lambda_{\max }\right]$. If $x_{b}\left(\lambda_{2}\right) \notin \widetilde{\mathcal{D}}\left(\lambda_{1}\right)$, then it must be the case that $x_{b}\left(\lambda_{2}\right)>$ $x_{b}\left(\lambda_{1}\right)$ and the lemma is proved. Suppose $x_{b}\left(\lambda_{2}\right) \in \widetilde{\mathcal{D}}\left(\lambda_{1}\right)$. For any $x \in \widetilde{\mathcal{D}}\left(\lambda_{1}\right)$, consider the following differences:

$$
W^{b}\left(\lambda_{2}, x\right)-W^{b}\left(\lambda_{1}, x\right)=\widetilde{\theta} \ln \left\{\frac{w \lambda_{2}\left[1-\tau_{b}(x)\right]-\gamma_{b}}{w \lambda_{1}\left[1-\tau_{b}(x)\right]-\gamma_{b}}\right\}-(1-\alpha-\zeta) \theta \ln \left(\frac{\lambda_{2}}{\lambda_{1}}\right) .
$$


Define the function

$$
\Psi(x)=\frac{w \lambda_{2}\left[1-\tau_{b}(x)\right]-\gamma_{b}}{w \lambda_{1}\left[1-\tau_{b}(x)\right]-\gamma_{b}}
$$

Notice that $\lambda_{2}>\lambda_{1}$ and $x \in \widetilde{\mathcal{D}}\left(\lambda_{1}\right)$ implies $w \lambda_{2}\left[1-\tau_{b}(x)\right]>w \lambda_{1}\left[1-\tau_{b}(x)\right]>0$. Hence $\ln [\Psi(x)]>0$ for all $x \in \widetilde{\mathcal{D}}\left(\lambda_{1}\right)$. In addition, $\Psi(x)$ is strictly increasing in $x$ as $\Psi^{\prime}(x)>0$ for all $x>0$. This means the differences $W^{b}\left(\lambda_{2}, x\right)-W^{b}\left(\lambda_{1}, x\right)$ is strictly increasing in $x$ over the interval $\widetilde{\mathcal{D}}\left(\lambda_{1}\right)$.

By the definition of $x_{b}(\lambda)$, we have

$$
W^{b}\left[\lambda_{2}, x_{b}\left(\lambda_{2}\right)\right]-W^{b}\left[\lambda_{2}, x_{b}\left(\lambda_{1}\right)\right] \geq 0 \geq W^{b}\left[\lambda_{1}, x_{b}\left(\lambda_{2}\right)\right]-W^{b}\left[\lambda_{1}, x_{b}\left(\lambda_{1}\right)\right]
$$

Suppose the contrary that $x_{b}\left(\lambda_{2}\right)<x_{b}\left(\lambda_{1}\right)$. Since $W^{b}\left(\lambda_{2}, x\right)-W^{b}\left(\lambda_{1}, x\right)$ is strictly increasing in $x$, we have

$$
W^{b}\left[\lambda_{2}, x_{b}\left(\lambda_{2}\right)\right]-W^{b}\left[\lambda_{1}, x_{b}\left(\lambda_{2}\right)\right]<W^{b}\left[\lambda_{2}, x_{b}\left(\lambda_{1}\right)\right]-W^{b}\left[\lambda_{1}, x_{b}\left(\lambda_{1}\right)\right]
$$

which contradicts (A.2). Hence, it must be the case that $x_{b}\left(\lambda_{2}\right) \geq x_{b}\left(\lambda_{1}\right)$.

Proof of Proposition 1. The following lemma is used in the proof of Proposition 1 and Proposition 2. In words, Lemma 3 states that if an agent with ability $\lambda_{1}$ prefers to be a car owner in locations with distance $x_{1}$ from the CBD, then any agent with ability $\lambda_{2} \geq \lambda_{1}$ would also choose to be a car owner in any location further than $x_{1}$.

Lemma 3. For any $\lambda_{1}$ and $\lambda_{2}$ in $\left[\lambda_{\min }, \lambda_{\max }\right], \lambda_{2} \geq \lambda_{1} \geq \lambda_{\min }$, and for any $x_{2} \geq x_{1} \geq 0$,

$$
W^{c}\left(\lambda_{1}, x_{1}\right) \geq W^{b}\left(\lambda_{1}, x_{1}\right) \quad \text { implies } \quad W^{c}\left(\lambda_{2}, x_{2}\right) \geq W^{b}\left(\lambda_{2}, x_{2}\right),
$$

with strict inequality holds if $\left(\lambda_{2}, x_{2}\right)>\left(\lambda_{1}, x_{1}\right)$.

Proof of Lemma 3. Using (12) through (14), one can derive the explicit form of $W^{c}(\lambda, x)$,

$$
\begin{aligned}
W^{c}(\lambda, x)= & \xi+\tilde{\theta} \ln \left\{w \lambda\left[1-\tau_{c}(x)\right]-\left(\gamma_{c}+p_{c}\right)\right\}-\zeta \ln q(x)-(1-\alpha-\zeta) \theta\left(\ln \psi_{c}+\ln w \lambda\right) \\
& -(1-\alpha-\zeta) \eta x .
\end{aligned}
$$

Fix $\lambda$. For any $x$ such that $w \lambda\left[1-\tau_{b}(x)\right] \geq \gamma_{b}$ and $w \lambda\left[1-\tau_{c}(x)\right] \geq \gamma_{c}+p_{c}, W^{c}(x, \lambda) \geq W^{b}(x, \lambda)$ if and only if

$$
\tilde{\theta} \ln \left\{\frac{w \lambda\left[1-\tau_{c}(x)\right]-\left(\gamma_{c}+p_{c}\right)}{w \lambda\left[1-\tau_{b}(x)\right]-\gamma_{b}}\right\} \geq(1-\alpha-\zeta) \theta \ln \left(\frac{\psi_{c}}{\psi_{b}}\right)
$$

$$
\Leftrightarrow w \lambda(\beta-1)+w \lambda\left[\tau_{b}(x)-\beta \tau_{c}(x)\right] \geq \beta\left(\gamma_{c}+p_{c}\right)-\gamma_{b},
$$

where $\beta \equiv\left(\psi_{b} / \psi_{c}\right)^{1-\widetilde{\alpha}-\widetilde{\zeta}}>1$. To prove the lemma, it suffice to show that the left-hand side of (A.3) is strictly increasing in $x$ and in $\lambda$.

First, as $\beta>1$ and $1-\tau_{c}(x)>0$, we have

$$
\beta\left[1-\tau_{c}(x)\right]-\left[1-\tau_{b}(x)\right]>\tau_{b}(x)-\tau_{c}(x)=\left(\psi_{b}-\psi_{c}\right) x
$$


which is nonnegative for all $x \geq 0$. Hence the left-hand side of (A.3) is strictly increasing in $\lambda$. Second, consider the following expression

$$
\tau_{b}(x)-\beta \tau_{c}(x)=\left[\psi_{b}-\left(\frac{\psi_{b}}{\psi_{c}}\right)^{1-\widetilde{\alpha}-\tilde{\zeta}} \psi_{c}\right] x=\left[\left(\psi_{b}\right)^{\widetilde{\alpha}+\widetilde{\zeta}}-\left(\psi_{c}\right)^{\widetilde{\alpha}+\tilde{\zeta}}\right]\left(\psi_{b}\right)^{1-\widetilde{\alpha}-\tilde{\zeta}} x .
$$

Since $\psi_{b}>\psi_{c}$ and $\widetilde{\alpha}+\widetilde{\zeta} \in(0,1)$, the above expression is strictly increasing in $x$. Hence the left-hand side of (A.3) is also strictly increasing in $x$. This completes the proof of Lemma 3.

The following is the proof of Proposition 1. Define the following subsets in $\left[\lambda_{\min }, \lambda_{\max }\right]$,

$$
\begin{aligned}
& \Lambda_{c}=\left\{\lambda \in\left[\lambda_{\min }, \lambda_{\max }\right]: V^{c}(\lambda) \geq V^{b}(\lambda)\right\}, \\
& \Lambda_{b}=\left\{\lambda \in\left[\lambda_{\min }, \lambda_{\max }\right]: V^{c}(\lambda) \leq V^{b}(\lambda)\right\} .
\end{aligned}
$$

$\Lambda_{c} \cap \Lambda_{b}$ is nonempty if there exists at least one ability in $\left[\lambda_{\min }, \lambda_{\max }\right]$ that solves $V^{c}(\lambda)=V^{b}(\lambda)$. This means both $\Lambda_{b}$ and $\Lambda_{c}$ are nonempty. By the continuity of $V^{c}(\lambda)$ and $V^{b}(\lambda), \Lambda_{c}$ and $\Lambda_{b}$ must be closed sets. Hence the maximum and minimum elements of these sets exist.

Let $\underline{\lambda}_{c}$ be the minimum element in $\Lambda_{c}$ and $\bar{\lambda}_{b}$ be the maximum element in $\Lambda_{b} . \Lambda_{c} \cap \Lambda_{b}$ is nonempty implies $\bar{\lambda}_{b} \geq \underline{\lambda}_{c}$. Suppose $x_{b}\left(\bar{\lambda}_{b}\right)>x_{c}\left(\underline{\lambda}_{c}\right)$. Since $\underline{\lambda}_{c} \in \Lambda_{c}$ and $\bar{\lambda}_{b} \in \Lambda_{b}$, we have

$$
V^{c}\left(\underline{\lambda}_{c}\right) \equiv W^{c}\left[\underline{\lambda}_{c}, x_{c}\left(\underline{\lambda}_{c}\right)\right] \geq W^{b}\left[\underline{\lambda}_{c}, x_{c}\left(\underline{\lambda}_{c}\right)\right]
$$

and

$$
V^{b}\left(\bar{\lambda}_{b}\right) \equiv W^{b}\left[\bar{\lambda}_{b}, x_{b}\left(\bar{\lambda}_{b}\right)\right] \geq W^{c}\left[\bar{\lambda}_{b}, x_{b}\left(\bar{\lambda}_{b}\right)\right]
$$

By Lemma $3, x_{b}\left(\bar{\lambda}_{b}\right)>x_{c}\left(\underline{\lambda}_{c}\right)$ implies

$$
V^{c}\left(\bar{\lambda}_{b}\right) \geq W^{c}\left[\bar{\lambda}_{b}, x_{b}\left(\bar{\lambda}_{b}\right)\right]>W^{b}\left[\bar{\lambda}_{b}, x_{b}\left(\bar{\lambda}_{b}\right)\right] \equiv V^{b}\left(\bar{\lambda}_{b}\right)
$$

which means $\bar{\lambda}_{b} \notin \Lambda_{b}$. Hence $x_{b}\left(\bar{\lambda}_{b}\right) \leq x_{c}\left(\underline{\lambda}_{c}\right)$. By Lemma 1 , no bus users would live further away from the CBD than distance $x_{b}\left(\bar{\lambda}_{b}\right)$. Similarly by Lemma 2, all car owners would be contained inside the ring with inner radius $x_{c}\left(\underline{\lambda}_{c}\right)$ and outer radius $x_{c}\left(\bar{\lambda}_{c}\right)$, where $\bar{\lambda}_{c}$ is the maximum element in $\Lambda_{c}$. The two types of agents are thus separated in terms of location. Define $\bar{x}=x_{b}\left(\bar{\lambda}_{b}\right)$ and $\tilde{x}=x_{c}\left(\bar{\lambda}_{c}\right)$. Both $\bar{x}$ and $\tilde{x}$ are unique as $\bar{\lambda}_{b}$ and $\bar{\lambda}_{c}$ are unique. This completes the proof.

Proof of Proposition 2. Part (i). In the proof of Proposition 1 it is shown that $x_{b}\left(\bar{\lambda}_{b}\right) \leq x_{c}\left(\underline{\lambda}_{c}\right)$. The remaining task is to show that in equilibrium $\bar{\lambda}_{b}=\underline{\lambda}_{c}$ and $x_{b}\left(\bar{\lambda}_{b}\right)=x_{c}\left(\underline{\lambda}_{c}\right)$. If a critical ability level $\bar{\lambda}$ exists, then $\bar{\lambda} \in \Lambda_{c} \cap \Lambda_{b}$ and $\bar{\lambda}_{b} \geq \bar{\lambda} \geq \underline{\lambda}_{c}$. If $\bar{\lambda}_{b}=\underline{\lambda}_{c}$, then there exists at most one element in $\Lambda_{c} \cap \Lambda_{b}$ and hence $\bar{\lambda}$ is unique.

Since $\underline{\lambda}_{c} \leq \lambda$ for all $\lambda \in \Lambda_{c}$, it follows that $x_{c}\left(\underline{\lambda}_{c}\right) \leq \tilde{x}$. As argued in the text, all land within the city boundary $\mathbf{C}$ must be occupied by residences. This rules out the possibility of $x_{b}\left(\bar{\lambda}_{b}\right)<x_{c}\left(\underline{\lambda}_{c}\right)$. Hence $x_{b}\left(\bar{\lambda}_{b}\right)=x_{c}\left(\underline{\lambda}_{c}\right)=\bar{x}$.

Suppose the contrary that $\bar{\lambda}_{b}>\underline{\lambda}_{c}$. Then by Lemma 3,

$$
V^{c}\left(\underline{\lambda}_{c}\right) \equiv W^{c}\left(\underline{\lambda}_{c}, \bar{x}\right) \geq W^{b}\left(\underline{\lambda}_{c}, \bar{x}\right),
$$

which implies

$$
V^{c}\left(\bar{\lambda}_{b}\right) \geq W^{c}\left(\bar{\lambda}_{b}, \bar{x}\right)>W^{b}\left(\bar{\lambda}_{b}, \bar{x}\right) \equiv V^{b}\left(\bar{\lambda}_{b}\right)
$$


The second condition implies $\bar{\lambda}_{b} \notin \Lambda_{b}$, which is a contradiction. Hence $\bar{\lambda}_{b}=\underline{\lambda}_{c}=\bar{\lambda}$ and $x_{b}(\bar{\lambda})=$ $x_{c}(\bar{\lambda})=\bar{x}$.

Part (ii). By Lemmas 1 and 2, $\lambda>\bar{\lambda}$ implies $x_{c}(\lambda) \geq x_{c}(\bar{\lambda})$ and $x_{b}(\lambda) \geq x_{b}(\bar{\lambda})$. Since

$$
V^{c}(\bar{\lambda}) \equiv W^{c}\left[\bar{\lambda}, x_{c}(\bar{\lambda})\right]=W^{b}\left[\bar{\lambda}, x_{b}(\bar{\lambda})\right] \equiv V^{b}(\bar{\lambda})
$$

it follows from Lemma 3 that

$$
V^{c}(\lambda) \geq W^{c}\left[\lambda, x_{b}(\lambda)\right] \geq W^{b}\left[\lambda, x_{b}(\lambda)\right] \equiv V^{b}(\lambda)
$$

Since $\bar{\lambda}$ is the unique ability level so that $V^{c}(\lambda)=V^{b}(\lambda)$, it follows that $V^{c}(\lambda)>V^{b}(\lambda)$.

Proof of Proposition 3. Since $x_{b}(\lambda)$ and $x_{c}(\lambda)$ are both continuous functions, it follows that $x(\lambda)$ is continuous over $\left[\lambda_{\min }, \bar{\lambda}\right)$ and $\left(\bar{\lambda}, \lambda_{\max }\right]$. According to Proposition $2 \operatorname{part}(\mathrm{i}), x_{b}(\bar{\lambda})=x_{c}(\bar{\lambda})$. Hence $x(\lambda)$ is also continuous at $\lambda=\bar{\lambda}$.

According to Lemmas 1 and $2, \lambda_{\min } \leq \lambda_{1}<\lambda_{2} \leq \lambda_{\max }$ implies $x\left(\lambda_{1}\right) \leq x\left(\lambda_{2}\right)$. Suppose the contrary that $x\left(\lambda_{1}\right)=x\left(\lambda_{2}\right)=\chi \geq 0$. This in turn implies that all agents with ability $\lambda \in\left[\lambda_{1}, \lambda_{2}\right]$ would reside in the $\operatorname{arc} \mathcal{C}(\chi) \equiv\{(\chi, v): v \in[0,2 \pi \Lambda]\}$. The total mass of these agents is $F\left(\lambda_{2}\right)-$ $F\left(\lambda_{1}\right)>0$. But the total supply of land in $\mathcal{C}(\chi)$ is of measure zero. This means the land market in $\mathcal{C}(\chi)$ would not be cleared. Hence this cannot be an equilibrium.

Derivations of (20) AND (21). The land market clearing conditions mean that for any $\lambda \in$ $\left[\lambda_{\min }, \lambda_{\max }\right]$,

$$
\begin{gathered}
l(\lambda) f(\lambda) d \lambda=[1+2 \pi \Lambda x(\lambda)] d x(\lambda), \\
\Rightarrow x^{\prime}(\lambda)=\frac{l(\lambda) f(\lambda)}{1+2 \pi \Lambda x(\lambda)}
\end{gathered}
$$

For all $\lambda \leq \bar{\lambda}$, define $\widetilde{q}(\lambda) \equiv q\left[x_{b}(\lambda)\right]$ so that $\widetilde{q}^{\prime}(\lambda)=q^{\prime}\left[x_{b}(\lambda)\right] x_{b}^{\prime}(\lambda)$. Meanwhile the first-order condition characterizing $x_{b}(\lambda)$ can be expressed as

$$
q^{\prime}\left[x_{b}(\lambda)\right] l_{b}(\lambda)=-w \lambda\left\{\psi_{b}+\frac{(1-\alpha-\zeta) \eta}{\widetilde{\theta}}\left[1-\psi_{b} x_{b}(\lambda)-\frac{\gamma_{b}}{w \lambda}\right]\right\}
$$

Combining (A.6) and (A.7) gives (21). On the other hand, Equation (A.6) can be rewritten as (20). The system of differential equations that characterizes the car owner's problem can be derived in the same fashion.

A.2. Numerical Algorithm. Each steady state is computed as follows. Given an initial guess of $\bar{\lambda}$, the end of the bus-users, $\bar{x}$, is computed using (22). Then $x_{b}(\lambda)$ and $q_{b}(\lambda)$ are found by solving the bus-user's boundary value problem (BVP). The BVP is solved using a homotopy algorithm: the parameters $\eta$ and $\Lambda$ are set to zero, reducing the BVP to an initial value problem (IVP), then the parameters are slowly incremented to their actual values using the solution from the previous parameterization as an initial guess. At each iteration of the homotopy the BVP is solved using a collocation method. Homotopy is required to maintain numerical stability. Next the car-owner's IVP is solved using the initial conditions $x_{c}(\bar{\lambda})=\bar{x}$ and $q_{c}(\bar{\lambda})=q_{b}(\bar{\lambda})$. Then the guess on $\bar{\lambda}$ is updated. This process is repeated until $\left|q_{c}\left(\lambda_{\max }\right)-q_{A}\right|$ is less than the desired tolerance. 


\section{A.3. Data}

A.3.1. Number of households. The number of households in each decennial year is approximated using U.S. Census data for a sample consisting of the 50 most populous cities in 1900. Since data on household size and number is unavailable, it is assumed that the average size of households living in these cities is the same as the average size of nonfarm households in the entire country. The latter is approximated as the ratio of nonfarm population to nonfarm households and is based on data from the Historical Statistics of the United States, Colonial Times to 1970, Series A 73-81 and 350-352. For each year, the number of households living in the sample cities is approximated as the population of the sample cities divided by the estimate of average household size.

A.3.2. Car ownership. For the period 1947-1970, data on the percentage of U.S. households owning a car are taken from the Historical Statistics of the United States, Colonial Times to 1970, Series Q 175-186. Data for the early years is scarce. The only source available is a survey on household expenditures conducted by the Bureau of Labor Statistics between 1934 and 1936 and reported in the Monthly Labor Statistics (March 1940) pp. 556-566. For the years 1910 and 1920, car ownership is approximated as number of register passenger cars per household. This approximation can be justified by the fact that very few households owned more than one car in the early years. According to the Survey of Consumer Finance, only 3\% of households owned two or more cars in 1949. Presumably the percentages were even lower in the 1910s and the 1920s.

A.3.3. Distribution of abilities. The term $w \lambda$, hereafter referred to as maximum five-year earnings, represents the total earnings that a household with ability $\lambda$ can make in five years if it spends all of its time endowment on work. If the household spends $\tau_{b}(x)$ time on commuting and $\tau_{b}(z)$ time on leisure travel, then its actual wage income is $w \lambda\left[1-\tau_{b}(x)-\tau_{b}(z)\right]$. Since there are no empirical observations on $w \lambda$, its distribution must be constructed. The moments for $w \lambda$ can then be used to compute the moments for $\lambda$. The method used here takes into account that (i) there was an increase in the labor force participation rate of married women and (ii) there was decline in working hours among U.S. workers during the 1910-1970 period.

First, construct a distribution of maximum five-year earnings for individuals in each time period. Since earnings data by sex are not available, this is a distribution for all employed workers. Second, classify households into two groups: those with one income earner and those with two. The fraction of households with two income earners is equated to the percentage of married women in the total labor force. Let $y_{t}$ be the maximum five-year earnings for an individual in period $t$, and $\varphi_{t}$ be the fraction of households with two income earners. Then the maximum five-year earnings for an average household is

$$
E\left(w_{t} \lambda_{t}\right)=E\left[\left(1-\varphi_{t}\right) y_{t}+\varphi_{t} 2 y_{t}\right]=\left(1+\varphi_{t}\right) E\left(y_{t}\right)
$$

The variance of $w_{t} \lambda_{t}$ is given by

$$
\operatorname{var}\left(w_{t} \lambda_{t}\right)=\left(1+\varphi_{t}\right)^{2} \operatorname{var}\left(y_{t}\right)
$$

Using these values, one can derive the mean and variance of $\ln \lambda_{t}$. Normalize the mean of $\lambda_{t}$ to one so that

$$
E\left(w_{t} \lambda_{t}\right)=w_{t}=\left(1+\varphi_{t}\right) E\left(y_{t}\right),
$$


and

$$
\mu_{t}+\frac{1}{2} \sigma_{t}^{2}=0
$$

Using (A.9),

$$
\operatorname{var}\left(y_{t}\right)=\left(\frac{w_{t}}{1+\varphi_{t}}\right)^{2} \operatorname{var}\left(\lambda_{t}\right)=\left(\frac{w_{t}}{1+\varphi_{t}}\right)^{2} \exp \left[\sigma_{t}^{2}-1\right]
$$

Equations (A.10) and (A.11) are then used to solve for the parameters $\mu_{t}$ and $\sigma_{t}^{2}$.

The rest of this section describes how the distribution of individuals' earnings is constructed. First, to construct the distribution for the decennial years from 1940 to 1970 the following four sets of data are used: (i) the average hourly earnings of employees by major industries over the period 1936-1970, (ii) the number of employees by major industries during the same time period, (iii) average weekly hours of nonagricultural workers, and (iv) the number of hours spent on traveling per day. The first two sets of data can be used to construct a cross-sectional distribution of average hourly earnings for the years between 1936 and 1970. This is used to approximate the distribution of hourly wage rates for individual workers. Data on average hourly earnings and the total number of employees by industry are taken from the Statistical Abstract of the United States. Data on average hourly earnings are deflated by the consumer price index.

The other two sets of data are used to construct the total amount of time available in any given year as the sum of average weekly hours of nonagricultural workers times 52 weeks and the number of hours spent on traveling per day times 365 days a year. This takes into account that some waking hours are used for leisure activities (other than leisure travel) that are not accounted for by the model and working hours declined in the United States during the period in question. (See the Historical Statistics of the United States: Millennial Edition Table Ba45764588.) As for the time spent on traveling, the only data source available for the pre-1970 period is the 1965-1966 Time Use Study. The results of this study are reported in Egerton et al. (2005). In 1965 and 1966, an average person aged 18-65 spent about 79 minutes each day traveling. This includes travel for work, leisure, and errands. Since no other data source on traveling time is available, it is assumed that an average worker spends 79 minutes a day on travel during the 1910-1970 period.

For example, take the year 1970. In order to construct the distribution of five-year maximum earnings for individual workers, assume all workers remain in the same industry during the 1966-1970 period. Let $e_{i t}$ denote average hourly earnings for an employee and $s_{i t}$ be the share of all workers in industry $i$ in year $t$. Let $h_{t}$ denote the total time available for an average worker in year $t$. The mean and variance of maximum five-year earnings in 1970 is, respectively, given by

$$
\begin{aligned}
E\left(y_{1970}\right) & =\sum_{i} s_{i, 1970} \sum_{t=1966}^{1970} e_{i t} h_{t}, \\
\operatorname{var}\left(y_{1970}\right) & =\sum_{i} s_{i, 1970}\left[\sum_{t=1966}^{1970} e_{i t} h_{t}-E\left(y_{1970}\right)\right]^{2} .
\end{aligned}
$$

The same procedure is used to determine the values of $E\left(y_{t}\right)$ and $\operatorname{var}\left(y_{t}\right)$ for $t=1940,1950$, and 1960.

This procedure is not used for $t=1910,1920$, and 1930 because data on average hourly earnings and employment by industry are scarce prior to 1930. For these years, the maximum five-year earnings for an average worker is computed with the help of the real wage index 
reported in Williamson (1995). Specifically, let $\left\{\phi_{t}\right\}$ denote Williamson's index. The average hourly earnings for an average worker in year $t=1906, \ldots, 1930$ is computed by

$$
\bar{e}_{t}=\frac{\phi_{t}}{\phi_{1936}} \sum_{i} s_{i, 1936} e_{i, 1936} .
$$

The maximum five-year earnings for an average worker is then given by $E\left(y_{t}\right)=\bar{e}_{t} h_{t}$. The variance is computed under the assumption that the ratio $E\left(y_{t}\right) / \sqrt{\operatorname{var}\left(y_{t}\right)}$ has been constant throughout the period 1910-1940.

A.3.4. Paved urban roads. The time series of paved urban roads per urban population is obtained as follows. For the period 1941-1970, the total mileage of paved urban roads is obtained from various issues of Highway Statistics. This is then divided by the size of the urban population as reported in the Historical Statistics of the United States, Colonial Times to 1970. For the period 1920-1940, data on the total miles of surfaced urban roads is available from Highway Statistics; however, the breakdown into paved and unpaved roads is unavailable. This breakdown is approximated by computing the share of surfaced roads that are paved for each year from 1941 to 1970 and extending the linear trend in this share back to 1920 . Note that a significant linear time trend in these shares is observed. For the period 1906-1920, since there are no data available, the figures on paved urban roads are obtained by assuming that the total mileage of paved roads has been increasing at the same rate throughout the period 1906-1940.

A.3.5. Household earnings. For 1910 and 1920, household earnings are equated to individual nonfarm earnings obtained from Historical Statistics of the United States: Millennial Edition Table Ba4280-4282. Individual earnings provide a good proxy because the labor force participation rate of married women was very low during these years. From 1930 to 1960, household earnings are given by individual earnings in the nonagricultural sector times $(1+$ married women labor force participation rate). Data on wage and salary disbursements (individual earnings) can be found in the National Income and Product Accounts Table 2.2A. The total number of employed workers in the nonagricultural sector and married women's labor force participation rates can be found on the website of the U.S. Census Bureau $<$ http://www.census.gov/compendia/statab/hist_stats.html > . For 1970, household earnings are a weighted average of urban family and individual earnings. The data are obtained from the 1970 U.S. Census, Table 257. The reported values of household earnings are five-year averages. All values are deflated by the CPI.

\section{REFERENCES}

Baum-Snow, N., "Did Highways Cause Suburbanization?" Quarterly Journal of Economics 122 (2007a), 775-805.

, "Suburbanization and Transportation in the Monocentric Model," Journal of Urban Economics 62 (2007b), 405-23.

Boustan, L. P., "Was Postwar Suburbanization "White Flight"? Evidence from the Black Migration," National Bureau of Economic Research, Inc., NBER Working Papers: No. 13543, 2007.

Bradford, D. F., AND H. H. Kelejian, "An Econometric Model of the Flight to the Suburbs," Journal of Political Economy 81 (1973), 566-89.

Chatterjee, S., and G. A. Carlino, "Aggregate Metropolitan Employment Growth and the Deconcentration of Metropolitan Employment," Journal of Monetary Economics 48 (2001), 549-83.

Clark, C., "Urban Population Densities," Journal of the Royal Statistical Society Series A 114 (1951), 490-96.

Cullen, J. B., And S. D. LevitT, “Crime, Urban Flight, and the Consequences for Cities," The Review of Economics and Statistics 81 (1999), 159-69.

Edmonston, B., Population Distribution in American Cities (Lexington: Lexington Books, 1975).

FARLEY, R., "Residential Segregation in Urbanized Areas of the United States in 1970: An Analysis of Social Class and Racial Differences," Demography 14 (1977), 497-518.

Frey, W. H., "Central City White Flight: Racial and Nonracial Causes," American Sociological Review 44 (1979), 425-48. 
Fujita, M., AND H. Ogawa, "Multiple Equilibria and Structural Transition of Non-Monocentric Urban Configurations," Regional Science and Urban Economics 12 (1982), 161-96.

Glaeser, E., And M. Kahn, "Sprawl and Urban Growth,” in J. V. Henderson and J. Thisse, eds., Handbook of Regional and Urban Economics 4 (North Holland Press, 2004), 2481-527.

,,-- and J. Rappaport, "Why Do the Poor Live in Cities? The Role of Public Transportation," Journal of Urban Economics 63 (2008), 1-24.

Goldberg, M., And J. Mercer, The Myth of North American City (Vancouver: The University of British Columbia Press, 1986).

Grubb, W. N., "The Flight to the Suburbs of Population and Employment, 1960-70," Journal of Urban Economics 11 (1982), 348-67.

Guest, A. M., "The Changing Racial Composition of Suburbs, 1950-1970," Urban Affairs Quarterly 14 (1978), 195-206.

Hawley, A. H., The Changing Shape of Metropolitan America: Deconcentration Since 1920 (Glencoe: The Free Press, 1956).

Jones, D., Urban Transit Policy: An Economic and Political History (Englewood Cliffs: Prentice-Hall, Inc., 1985).

Katzman, M., "The Contribution of Crime to Urban Decline,” Urban Studies 17 (1980), 277-86.

Lebergott, S., Consumer Expenditures: New Measures and Old Motives (Princeton: Princeton University Press, 1996).

LeRoy, S. F., And J. Sonstelie, "Paradise Lost and Regained: Transportation Innovation, Income, and Residential Location," Journal of Urban Economics 13 (1983), 67-89.

Lucas, R. E., and E. Rossi-Hansberg, "On the Internal Structure of Cities," Econometrica 70 (2002), $1445-76$.

Margo, R. A., "Explaining the Postwar Suburbanization of Population in the United States: The Role of Income," Journal of Urban Economics 31 (1992), 301-10.

Marshall, H., "White Movement to the Suburbs: A Comparison of Explanations," American Sociological Review 44 (1979), 975-94.

McDonald, J. F., "Econometric Studies of Urban Population Density: A Survey," Journal of Urban Economics 26 (1989), 361-85.

Mieszkowski, P., And E. S. Mills, “The Causes of Metropolitan Suburbanization,” Journal of Economic Perspectives 7 (1993), 135-47.

Mills, E. S., Studies in the Structure of the Urban Economy (Baltimore: Johns Hopkins University Press, 1972).

— , AND L. S. LuBuELE, “Inner Cities,” Journal of Economic Literature 35 (1997), 727-56.

- ANd R. PRice, "Metropolitan Suburbanization and Central City Problems," Journal of Urban Economics 15 (1984), 1-17.

— , AND J. P. TAN, "A Comparison of Urban Population Density Functions in Developed and Developing Countries," Urban Studies 17 (1980), 313-21.

Moses, L., and H. Williamson, "The Location of Economic Activity in Cities," American Economic Review, Papers and Proceedings 57 (1967), 211-22.

RafF, D., And M. Trajtenberg, "Quality-Adjusted Prices for the American Automobile Industry: 19061940," in T. F. Bresnahan and R. J. Gordon, eds., The Economics of New Goods (Chicago and London: University of Chicago Press, 1997).

Sampson, R. J., And J. D. Wooldredge, "Evidence that High Crime Rates Encourage Migration Away from Central Cities," Sociology and Social Research 70 (1986), 310-14.

Sorensen, A., K. E. Taeuber, and L. J. Hollingsworth Jr., "Indexes of Racial Residential Segregation for 109 Cities in the United States," Sociological Focus 8 (1975), 125-42.

Sundaram, R., A First Course in Optimization Theory (Cambridge, UK: Cambridge University Press, 1996).

TAYLOR, G. R., "The Beginnings of Mass Transportation in Urban America, Parts I and II," The Smithsonian Journal of History 1 (1966), 35-50 and 51-54.

Ulmer, M. J., Capital in Transportation, Communications, and Public Utilities: Its Formation and Financing (Princeton: Princeton University Press, 1960).

WARD, D., Cities and Immigrants: A Geography of Change in Nineteenth-Century America (New York: Oxford University Press, 1971).

Warner JR., S. B., Streetcar Suburbs: The Process of Growth in Boston, 1870-1900 (Cambridge, MA: Harvard University Press, 1962).

White, M. J., "Firm Suburbanization and Urban Subcenters," Journal of Urban Economics 3 (1976), 32343.

Williamson, J. G., "The Evolution of Global Labor Markets since 1830: Background Evidence and Hypothesis," Explorations in Economic History 32 (1995), 141-96.

WiLson, W. J., The Truly Disadvantaged (Chicago: University of Chicago Press, 1987). 